Yerbilimleri, 2020, 41 (1), 30-55, DOI:10.17824/yerbilimleri.617852

Hacettepe Üniversitesi Yerbilimleri Uygulama ve Araştırma Merkezi Bülteni

Bulletin of the Earth Sciences Application and Research Centre of Hacettepe University

\title{
Deprem Kaynak Mekanizması Parametreleriyle Sayısal Tsunami Simülasyonları: 08 Eylül 2017 Chiapas-Meksika Depremi ( $M_{w}$ 8.2) ve Tsunamisi
}

Numerical Tsunami Simulations based on Earthquake Source Mechanism Parameters: A case study of the September 08, 2017 Chiapas-Mexico (Mw 8.2) Earthquake and Associated Tsunami

HAKAN TARIK MERIÇ ${ }^{1}$, SEDA YOLSAL-ÇEVIKBILEN * ${ }^{1}$, TUNCAY TAYMAZ ${ }^{1}$

${ }^{1}$ İstanbul Teknik Üniversitesi, Maden Fakültesi, Jeofizik Müh. Böl., Ayazağa Kampüsü, TR-34469, Maslak, Sarıyer, İstanbul, Türkiye

ÖZ

Geliş (received): 11 Eylül (September) 2019

Kabul (accepted) : 18 Nisan (April) 2020

Sismolojik gözlem ve verilerin ters çözüm işlemleri ile modellenmeleri, bir depremin kaynak mekanizması çözümünün ve kinematik ve dinamik kaynak parametrelerinin (fay düzlemine ait doğrultu, eğim, kayma açısı, deprem odak derinliği, sismik moment, fay uzunluğu, fay genişliği, maksimum ve ortalama yerdeğiştirme miktarı, gerilme düşümü, kırılma süresi vb) belirlenmesine olanak tanımaktadır. Bu parametreler, daha sonra yapılacak olan diğer çalışmalarda (örn., tsunami simülasyonları vb) giriş parametreleri olarak kullanılmaktadır. Bu çalışmada, 08 Eylül 2017 tarihinde Chiapas (Meksika) bölgesinde meydana gelen $\mathrm{M}_{\mathrm{w}}$ 8.2 büyüklüğündeki yıkıcı depremin kaynak mekanizması çözümü ve fay düzlemi üzerinde gerçekleşen kayma/yırtılma dağılımı, telesismik uzaklıklarda kaydedilen uzun periyotlu Pve $\mathrm{SH}$ - ve geniş-bantlı $\mathrm{P}$ - dalga şekillerinin modellenmesi sonucunda belirlenmiştir. Sonuçlar, 08 Eylül 2017 Chiapas (Meksika) depreminin çok küçük doğrultu atım bileşenine sahip normal faylanma mekanizmasıyla ve basit yapılı bir kırılmayla $54 \mathrm{~km}$ odak derinliğinde meydana geldiğini göstermektedir. Ayrıca, KB-GD uzanımlı fay düzlemi üzerinde gerçekleşen kırılmanın yaklaşık 125 km fay uzunluğuna ve 55 km fay genişliğine sahip bir alanda meydana geldiği, maksimum yerdeğiştirme miktarının ise yaklaşık olarak

https://doi.org/10.17824/yerbilimleri.617852

Seda YOLSAL-ÇEVIKBIILEN yolsalse@itu.edu.tr

${ }^{1}$ İstanbul Teknik Üniv., Maden Fak., Jeofizik Müh. Böl., Ayazağa Kampüsü, TR-34469, Maslak, Sarıyer, İstanbul, Türkiye, ORCID 0000-0001-9866-7847 ${ }^{1}$ İstanbul Teknik Üniv., Maden Fak., Jeofizik Müh. Böl., Ayazağa Kampüsü, TR-34469, Maslak, Sarıyer, İstanbul, Türkiye, ORCID 0000-0002-7250-4617 ${ }^{1}$ İstanbul Teknik Üniv., Maden Fak., Jeofizik Müh. Böl., Ayazağa Kampüsü, TR-34469, Maslak, Sarıyer, İstanbul, Türkiye, ORCID 0000-0001-6807-9622 
22.10 m olduğu saptanmıştır. Tekdüze (homojen) kayma dağılımı modeline ve 30 yay-sn çözünürlüklü GEBCO-BODC batimetri verisine dayalı olarak gerçekleştirilen sayısal tsunami simülasyonu ile deprem nedeniyle oluşan tsunami dalgalarının Pasifik okyanusu içerisinde ilerleyişi modellenerek çeşitli kıyılar için yapay tsunami dalgaları hesaplanmıştır. Hesaplanan tsunami dalgaları Derin Deniz Tsunami Belirleme ve Raporlama Şamandıraları (DART) ve gel-git ölçerler tarafından kaydedilen gerçek-zamanlı tsunami verileri ile karşılaştırılmıştır. Sonuç olarak, yapay tsunami dalgalarının gerçek-zamanlı kayıtlar ile nispeten uyumlu olduğu gözlenmiştir. Ancak, bu uyum özellikle okyanus/deniz içi şamandıra kayıtlarında daha fazla, kıyılardaki gel-git ölçer kayıtları için ise göreceli olarak daha azdır. Kıyılarda gözlenen tsunami dalgalarının daha iyi modellenebilmesinin, sayısal tsunami simülasyonlarında yüksek çözünürlüklü batimetri verisinin ve depreme ait sonlu-fay kayma dağılımı modelinin kullanılması ile mümkün olabileceği önerilmektedir.

Anahtar Kelimeler: Deprem, Kaynak mekanizması parametreleri, Kayma/Yırtılma Dağılımı, Orta Amerika Hendeği, Meksika, Sayısal Tsunami Simülasyonu.

\section{ABSTRACT}

Modeling of seismological data by inversion processes provides earthquake source mechanism solutions (e.g, strike, dip and rake angles of the fault plane, earthquake focal depth and seismic moment etc.) and kinematic and dynamic source parameters (e.g, fault length, fault width, maximum and average displacement amount, stress drop, rupture duration etc.). These parameters are used as input constraints for further analysis, particularly for tsunami modeling. In this study, we provide an example of teleseismic waveform inversion and numerical tsunami simulation studies in order to demonstrate the importance and necessity of seismological data in tsunami studies. We obtained source mechanism solution and finite-fault slip distribution model of the destructive 08 September 2017 ( $M_{w}$ 8.2) earthquake occurred in Chiapas (Mexico) region by inverting long period $P$ and $\mathrm{SH}$ - and broad-band P-waveforms recorded at telesismic stations. Overall results show that this earthquake occurred with a normal faulting mechanism and a very small strike-slip component at a focal depth of $54 \mathrm{~km}$, and a very simple rupture. In addition, slip distribution model of this event showed that the rupture occurred on the NW-SE trending fault plane has an area with a fault length of about $125 \mathrm{~km}$ and fault width of $55 \mathrm{~km}$ with a maximum displacement amount of $22.10 \mathrm{~m}$. Then, numerical tsunami simulations were performed based on a uniform slip model and GEBCO-BODC bathymetry data with 30 arcsec resolution, and propagation of tsunami waves trigerred by this earthquake in the Pacific Ocean have been modeled. Synthetic tsunami waves were calculated for various 
coasts and they were further compared with the real-time tsunami data recorded by Deep Ocean Assesment and Reporting of Tsunami (DART) and tide gauges. As a result, it is observed that synthetic tsunami waves are relatively compatible with real-time recordings. However, this consistency is particularly high for DART buoy records in open ocean and relatively less for tide gauge records on shorelines. Hence, we suggest that better modeling of tsunami waves recorded at tide gauges on the coasts might be achieved by using a high-resolution bathymetry data and a detailed finite-fault slip distribution model of earthquakes in numerical simulations.

Key words: Earthquake, Middle America Trench, Mexico, Numerical tsunami simulations, Source mechanism parameters, Slip/Rupture distribution.

\section{GíRiş}

Dünya üzerinde yıkıcı ve büyük depremler $(M>7.5)$ en yoğun olarak levha sınırları boyunca oluşmaktadır. Özellikle iki litosferik levhanın birbirine yaklaşıp çarpıştığı ve bu levhalardan bir tanesinin diğerinin altına dalıp batarak yok olduğu dalma batma zonları olası tsunami bölgeleridirler (örn., Güney Amerika, Sumatra-Endonezya, Japonya, Alaska, Kamçatka yarımadası, Kuril, Aleutan dalma batma zonları vb). Sismolojik çalışmalar, bu zonlar boyunca meydana gelen depremlerin farklı derinliklerde farklı odak mekanizması çözümleri gösterdiklerini ortaya koymaktadır (Taymaz vd., 1990, 1991; Bohnoff vd., 2005; Shaw ve Jackson, 2010; Ruiz-Constán vd., 2011; Yolsal-Çevikbilen ve Taymaz, 2012; Howell vd., 2017). Bu depremlerin büyük çoğunluğu yaklaşma ve çarpışma hareketini yansıtacak şekilde ters faylanma mekanizması ile meydana gelmektedir. Örneğin, 26 Aralık 2004 Kuzey Sumatra $\left(M_{w}\right.$ 9.3) depremi, Hint-Avustralya levhası ile Avrasya levhaları arasındaki çarpışma zonu boyunca, ters faylanma mekanizması ile $37 \mathrm{~km}$ odak derinliğinde kırılgan üst kabuk içerisinde oluşmuş ve çeşitli kıyılarda yaklaşık $10 \mathrm{~m}$ yüksekliğe kadar ulaşan tsunami dalgaları meydana getirmiştir. Tsunami dalgaları, deprem kaynağından başlayarak yayılma doğrultusu boyunca oldukça uzaklara ilerleyebilmiş ve pek çok ülkede (örn., Endonezya, Sri Lanka, Tayland, Malezya, Hindistan vb.) önemli boyutlarda can ve mal kaybına neden olmuştur (Lay vd., 2005; Sibuet vd., 2007; Franke vd., 2008). Benzer şekilde, 11 Mart 2011 tarihinde Japonya'da meydana gelen Tohoku-Oki mega-bindirme depremi $\left(M_{w} 9.0\right)$ ve tsunamisi de Japonya'da büyük ölçüde yıkıma neden olmuş, nükleer santrallerde ciddi boyutta hasara yol açmıştır (Ammon vd., 2011). Tarihsel dönem içerisinde Türkiye'de özellikle GB Anadolu kıyıları bulundukları konum itibarı ile yıkıcı tsunami dalgalarına maruz kalmıştır. Tarihsel kayıtlar ve kataloglar, bu tsunamilerin çoğunlukla deprem kaynaklı olduklarını ve bu depremlerin de sismik açıdan dünyanın en 
aktif bölgelerinden birisi olan Doğu Akdeniz Bölgesi'nde yer alan Hellenik dalma batma zonu boyunca meydana geldiklerini rapor etmektedirler (örn., Ambraseys, 1962; Antonopoulos, 1980; Guidoboni ve Comastri, 2005a,b; Papadopoulos vd., 2007; Yolsal vd., 2007). Depremlere ait kaynak mekanizması parametrelerinin tsunami dalga modelleme çalışmalarında başlangıç ve sınır koşullarının tanımlanmasında kullanılması, sismolojik gözlem ve analizlerin önemini ortaya koymaktadır (örn., Okal, 1988; Geist, 1999; Yolsal-Çevikbilen ve Taymaz, 2012; Ulutaş, 2013; Heidarzadeh vd., 2018; YolsalÇevikbilen vd., 2019). Okyanus veya deniz içerisinde meydana gelen, okyanus tabanında düşey yönde harekete neden olan eğim atımlı faylanma mekanizması (normal veya ters faylanma) ile sığ odak derinliğinde oluşan büyük ve yıkıcı depremlerin $\left(M_{w} \geq 7.5\right)$ tsunami dalgalarına neden oldukları bilinmektedir. Ancak yine de bazı depremlerin doğrultu atımlı faylanma mekanizması ile oluşmalarına rağmen tsunami dalgalarına neden oldukları gözlenmektedir. Örneğin, 28 Eylül 2018 Palu-Sulawesi (Endonezya) depremi $\left(M_{w} 7.5\right)$ baskın olarak doğrultu atımlı faylanma mekanizması ile meydana gelmesine rağmen, Palu körfezinde oldukça etkili tsunami dalgaları gözlenmiştir (örn., Jamelot vd., 2019; Pakoksung vd., 2019; Ulrich vd., 2019; Yolsal-Çevikbilen ve Taymaz, 2019). Son yıllarda yapılan sayısal tsunami simülasyonlarında yüksek çözünürlüklü batimetri verilerinin kullanılması ve uygun matematiksel modellerin geliştirilmesi ile tsunami dalgalarının okyanus/deniz içerisindeki yayılımları ve ulaştıkları kıyılardaki karakteristik özellikleri doğru bir şekilde belirlenebilmektedir. Matematiksel modellemelerde tanımlanan başlangıç ve sınır koşulları, sismolojik ve sismotektonik gözlemlerden elde edilen dinamik ve kinematik kaynak parametreleriyle tanımlanmaktadır (bkz. Heidarzadeh vd., 2018; Yolsal-Çevikbilen vd., 2019). Bir deprem oluştuğu andan itibaren çeşitli ulusal ve uluslararası merkezler (örn., Harvard-CMT, USGS, ISC vb.) otomatik ve hızlı analizler yaparak depreme ait kaynak mekanizması parametrelerini rapor etmektedir. Ancak, bu analizlerde farklı frekans içeriğine sahip sismik dalgaların modellenmesi nedeniyle moment tensör ters çözümlerinde farklılıklar meydana gelmektedir (Tan ve Taymaz, 2006; Taymaz vd., 2007; Yolsal, 2008). Özellikle, odak derinliğinin birçok deprem kataloğunda ters çözüm ile hesaplanmadığı ve bölgenin genel yapısı göz önünde bulundurularak sabit bir değer olarak alındığı görülmektedir. Örneğin, moment tensör kataloglarında belirtilen odak derinlikleri incelendiği zaman depremlerin büyük çoğunlukla $5,12,15,33$ km odak derinliğinde meydana geldikleri görülmektedir (bkz. Harvard-CMT, USGS moment tensor katalogları). Yine de gözlenen bu farklılıklara rağmen, mevcut ilksel çözümler depremlerin telesismik P- ve SH- cisim dalgası modelleme teknikleri ile daha detaylı olarak incelenmeleri aşamasında çok değerli ve vazgeçilemez ön bilgiler sağladıkları için önemlidirler. 
$\mathrm{Bu}$ çalışma, ters çözüm teknikleri ile sismolojik verilerden elde edilen deprem kaynak mekanizması parametrelerinin sayısal tsunami simülasyonlarında kullanılmasının gerekliliğinin ve öneminin örnek bir deprem ile gösterilmesini amaçlamaktadır. Bu kapsamda incelenen 08 Eylül 2017 Chiapas-Meksika ( $M_{w}$ 8.2) depremi, Orta Amerika Hendeği boyunca normal faylanma mekanizması ile oluşarak yıkıcı tsunami dalgalarına neden olan ve çok sayıda can ve mal kaybının gözlendiği bir depremdir. Depreme ait odak mekanizması çözümü ve fay düzlemi üzerinde gerçekleşen sonlu-fay kayma dağılımı modeli, telesismik istasyonlarda kaydedilen uzun periyotlu $\mathrm{P}$ - ve $\mathrm{SH}-$, ve geniş-bantlı $\mathrm{P}$ dalga şekillerinin ters çözüm işlemleri ile modellenmesi sonucunda belirlenmiştir. Deprem kaynak mekanizması parametreleri daha sonraki aşamada gerçekleştirilen sayısal tsunami simülasyonunda giriş parametreleri olarak kullanılmış ve tsunami dalgalarının okyanus içerisinde ilerleyişi modellenerek çeşitli kıyılar için yapay tsunami dalgaları hesaplanmıştır. Tsunami simülasyon sonuçları gerçek-zamanlı tsunami kayıtları ile karşılaştırılarak, elde edilen tüm sonuçlar tartışılmıştır.

\section{Eylül 2017 Chiapas-Meksika Depremi $\left(M_{w}\right.$ 8.2) ve Tsunamisi}

08 Eylül 2017 Chiapas-Meksika depremi ( $M_{w}$ 8.2) Cocos, Kuzey Amerika ve Karayip levhalarının birbirlerine göreceli olarak hareket ettikleri ve üçlü-kesişim noktası ile buluştukları Panama kırığının batısında Orta Amerika dalma-batma zonu boyunca meydana gelmiştir (USGS Enlem: 15.022 ${ }^{\circ}$ ve Boylam: -93.899; Şekil 1). Bu bölgede Cocos levhası, Kuzey Amerika ve Karayip levhalarının altına $6.4 \mathrm{~cm} / \mathrm{y} ı \mathrm{l}$ hız ile dalıp batarak yitmektedir (Singh vd., 2000). Deprem, meydana geldiği bölgede oldukça etkili olarak can ve mal kaybına yol açmıştır. Ramírez-Herrera vd. (2018) deprem nedeniyle 100'den fazla kişinin hayatını kaybettiğini, 1.5 milyondan fazla kişinin depremden etkilendiğini ve yaklaşık olarak 41.000 binanın yıkıldığını rapor etmişlerdir. 08 Eylül 2017 Chiapas depremi ( $\mathrm{M}_{\mathrm{w}}$ 8.2), 1932 Jalisco ve 1985 Mexico City depremlerinden sonra (Mendoza, 1993) Meksika bölgesinde meydana gelen en büyük depremdir (RamírezHerrera vd., 2018). Son 100 yıl içerisinde, bölgedeki levhaların yaklaşma hareketini yansıtacak şekilde ters faylanma mekanizması ile oluşan büyük bir deprem $\left(\mathrm{M}_{\mathrm{w}} \geq 7.0\right)$ gözlenmediği için, 2017 Chiapas depreminin meydana geldiği bölge Theuantepec Sismik Boşluğu olarak adlandırılmaktadır (Kelleher vd., 1973; Kelleher ve McCann, 1976; McNally ve Minster, 1981; Singh vd., 1981; Nishenko, 1991; Franco vd., 2005). Singh vd. (1981) Theuantepec Sismik Boşluğu'nun ya asismik bir zon olduğunu ya da bölgede büyük ve yıkıcı bir deprem oluşma periyodunun oldukça yüksek olduğunu önermiştir. Cocos ve Kuzey Amerika levhalarının arasında yer alan dalma batma zonu, Meksika bölgesinde düşük eğim açılı olup, Orta Amerika kısmında daha dik açıya sahiptir (Ponce vd., 1992). 


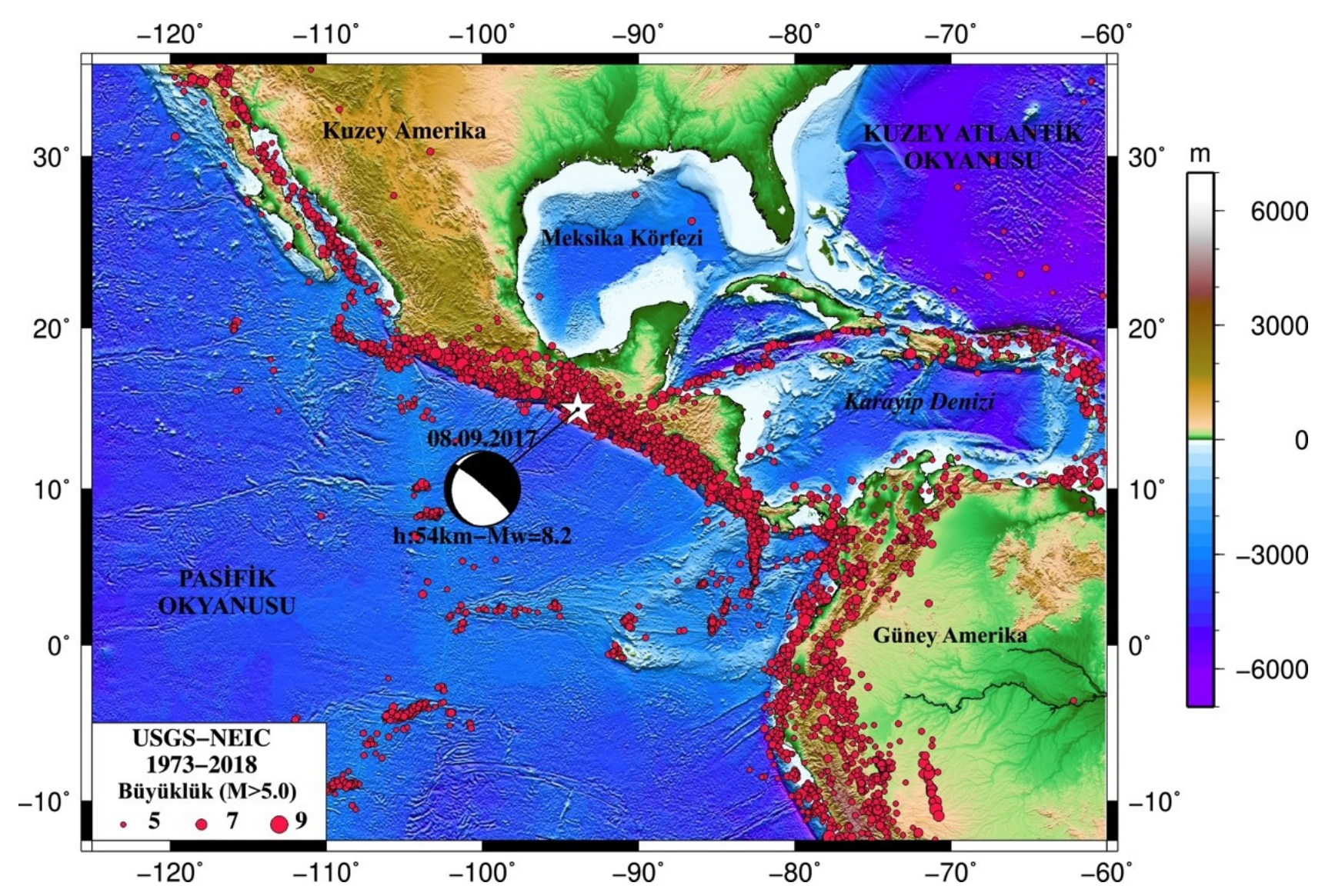

Şekil 1. Cocos, Kuzey Amerika and Karayipler levhaları arasında yer alan Orta Amerika dalma batma zonu boyunca meydana gelen deprem aktivitesi. Deprem bilgileri USGS NEIC (1973 - 2018) deprem kataloğundan alınmıştır. Batimetri ve topografya verileri ise sırasıyla GEBCO-BODC ve ETOPO1'dan alınmıştır. Beyaz yıldız 08 Eylül 2017 Chiapas-Meksika depreminin $\left(M_{w}\right.$ 8.2) lokasyonunu, odak küresi ise depremin odak mekanizması çözümünü göstermektedir.

Figure 1. Seismicity map of the region between the Cocos, North America and Caribbean plates. Epicentres are taken from USGS NEIC (1973 - 2018) earthquake catalogue. Bathymetry and topography data are taken from GEBCO-BODC and ETOPO1, respectively. The location (white star) and source mechanism solution of the September 08, 2017 Chiapas-Mexico earthquake are also given.

2017 Chiapas depreminin lokasyonu, Cocos levhası'nın Kuzey Amerika levhası altına dalıp batarak yittiği Meksika dalma batma zonuna yakın olsa da, deprem levha arası bir deprem olmayıp, dalan okyanusal levhanın üzerindeki normal faylanma ile ilişkili olarak meydana gelmiş levha içi bir deprem olarak tanımlanmaktadır. Deprem ve depremle ilişkili gelişen tsunaminin genel karakteristik özellikleri son dönemde bir çok araştırmacı tarafından çalışılmıştır (örn., Okuwaki ve Yagi, 2017; Ye vd., 2017; Adriano vd., 2018; Gusman vd., 2018; Chacón-Barrantes, 2018; Heidarzadeh vd., 2018; Jiménez, 2018; Ramírez-Herrera vd., 2018; Spagnotto vd., 2018; Guo vd., 2019; Song ve Ge, 2019). Ramírez-Herrera vd. (2018) yaptıkları tsunami sonrası arazi çalışmasında, Chiapas kıyılarında $41 \mathrm{~km}$ boyunca tsunami gözlemleri elde etmişlerdir. Huatulco gel-git ölçer istasyonunda depremden $12 \mathrm{dk}$ sonra tsunami dalgalarının kaydedildiğini, maksimum 
tırmanma yüksekliğinin Boca del Cielo kıyılarında yaklaşık 3 m olduğunu ve maksimum su basma uzaklığının ise Puerto Arista'da 190 m olduğunu belirlemişlerdir. Heidarzadeh vd. (2018) telesismik deprem verilerini ve tsunami kayıtlarını analizleyerek depreme ait sonlufay kayma dağılımı modelini belirlemiştir. Elde ettikleri modele göre 130 km x 80 km boyutlarındaki fay düzlemi üzerinde meydana gelen maksimum ve ortalama yerdeğiştirme miktarı sırasıyla $13.1 \mathrm{~m}$ ve 3.7 m'dir. Yapılan Coulomb statik gerilme analizleri, 2017 Chiapas depreminin Tehuantepec (Meksika) bölgesinin sığ kesimlerinde gerilme artışına neden olduğunu ve yakın gelecekte bu bölgede bindirme mekanizmasına sahip, olası büyük bir levha arası depremin $\left(\mathrm{M}_{\mathrm{w}}>7.9\right)$ meydana gelebileceğini göstermektedir (Heidarzadeh vd., 2018; Spagnotto vd., 2018). Jiménez (2018) ise normal faylanma mekanizması (doğrultu, eğim ve kayma açısı: $316^{\circ}, 80^{\circ},-91^{\circ}$ ) ile oluşan bu depremin basit bir kırılmayla 59 km odak derinliğinde meydana geldiğini, kırığın tek yönlü olarak KB'ya doğru ilerlediğini belirlemiştir. Sismik moment değerinin $\left(M_{0}\right) 2.55 \times 10^{21} \mathrm{Nm}$ olduğunu, enerjinin büyük oranda ilk 60 sn içerisinde boşaldığını ve kırılma süresinin yaklaşık 75 sn olduğunu rapor etmiştir. Ayrıca, depremin episantır noktasının KB'sında 75 km uzunluklu yüksek kayma bölgesinin oluştuğunu ve $180 \mathrm{~km}$ x $96 \mathrm{~km}$ boyutlarındaki fay düzlemi üzerinde meydana gelen maksimum yerdeğiştirme miktarının $14.5 \mathrm{~m}$ olduğunu da saptamıştır.

\section{VERI VE YÖNTEMLER}

\section{Telesismik P- ve SH- dalga şekli Modelleme}

$\mathrm{Bu}$ çalışmada gerçekleştirilen ters çözüm işlemlerinde telesismik uzaklıklardaki $\left(30^{\circ}-90^{\circ}\right)$ sismik istasyonlarda kaydedilen cisim dalgaları ( $\mathrm{P}$ - ve $\mathrm{SH}-$ ) ile yapay olarak üretilen dalga şekilleri ve genlikleri karşılaştırımıştır. Belirlenen kaynak mekanizması parametreleri, fayın doğrultu, eğim ve kayma açıları, deprem odak derinliği ve sismik momenti $\left(M_{0}\right)$ ve kırılmanın zaman içindeki davranışını gösteren kaynak zaman fonksiyonudur. Telesismik dalga şekli modelleme ters çözüm yönteminde, ikili kuvvet çifti (double-couple) yaklaşımı kullanılmakta ve ortamın nokta kaynak, doğrusal, homojen, elastik ve izotrop olduğu varsayılmaktadır. Telesismik deprem verileri, IRIS (Incorporated Research Institutions for Seismology) Uluslararası Sismoloji Veri Merkezi'nden alınarak analizlenmiştir. Depremlerin kaynak mekanizması çözümleri Zwick vd. (1994)'in geliştirdiği MT5 ters çözüm algoritması ile belirlenmiştir. Bu algoritma, telesismik uzun periyotlu (Long-Period) ve geniş-bantlı (Broad-Band) P- ve SH- dalga şekillerinin ters çözümüne dayalı olarak, depremin ikili kuvvet çifti kaynak mekanizması ve moment tensör çözümlerinin belirlenmesini sağlayan bir ters çözüm programıdır (McCaffrey vd., 1991). Doğrudan gelen P- ve SH- dalga 
şekilleri ve yüzeyden yansıyan pP, pS ve sS yansıma fazlarını içeren dalga şekilleri öncelikle hız kaydından yerdeğiştirme kaydına dönüştürülmüştür. Dalga genlikleri, geometrik yayılma ve elastik olmayan atenüasyon faktörlerine göre düzeltilmektedir. Atenüasyon için Futterman $\mathrm{Q}$ operatörü t ${ }^{*}, \mathrm{P}$ - ve $\mathrm{SH}$ - dalgaları için sırasıyla 1 sn ve 4 sn olarak alınmış ve telesismik uzaklıklardaki kayıtlar için sabit olarak kabul edilmiştir (Futterman, 1962). Ters çözüme giren telesismik istasyonların ağırlıklandırılması ise dalgaların ortalama göreceli genlikleri, dalga tipi ve odak küresi üzerindeki dağılımları dikkate alınarak yapılmıştır. Ters çözüm ile belirlenen kaynak parametrelerine ait hata miktarları Molnar ve Lyon-Caen (1989) ve Taymaz vd. (1990) tarafından önerilen klasik yöntemler ile belirlenmiştir. Telesismik dalga şekli modelleme ile ilgili daha detaylı bilgiye Taymaz vd. (1990, 1991), Tan ve Taymaz (2006), Yolsal-Çevikbilen ve Taymaz (2012, 2019) ve Fielding vd. (2013)' den ulaşılabilir.

\section{Sonlu-Fay Kayma/Yırtılma Dağılımının Modellenmesi}

Büyük depremlerin fay düzlemi boyunca gerçekleşen kayma/yırtılma dağılımları genelde karmaşık ve heterojen yapılıdırlar ve depremin ikincil etkileri üzerinde önem taşımaktadır (Yagi vd., 2012; Basili vd., 2013; Lay vd., 2013; Saltogianni vd., 2015; Yolsal-Çevikbilen vd., 2019). Bu çalışmada 2017 Chiapas - Meksika ( $M_{w}$ 8.2) depremine ait sonlu-fay kayma dağılımı modeli, ilk olarak Yagi ve Kikuchi (2000) tarafından geliştirilen ve daha sonra Yagi vd. (2012) tarafından çeşitli düzenlemelerle yenilenen ve birçok büyük depremin $\left(\mathrm{M}_{\mathrm{w}}>7.0\right)$ modellenmesinde kullanılan ters çözüm algoritması ile telesismik geniş bantlı P- dalga şekillerinin modellenmesi sonucunda saptanmıştır. Ters çözümde öncelikle fay düzlemi olarak seçilen düzlem $M \times N$ sayıda $x x$ uzunluğu ve $y y$ genişliğinde alt-düzleme bölünmüş ve her bir parça için $\tau$ yükselme zamanına sahip $L$ sayıda üçgenden oluşan kaynak zaman fonksiyonu tanımlanmıştır. Başlangıç modeli olarak, ilk aşamada belirlenen kaynak mekanizması parametreleri (doğrultu, eğim, kayma açıları ve deprem odak derinliği) kullanılmıştır. Kayma vektörü, ters çözüm işlemi sırasında tüm parçalar için sabit olarak alınabileceği gibi serbest bırakılarak birbirlerinden bağımsız olarak ta alınabilmektedir. Bu çalışmada kayma açısı serbest bırakılarak, ters çözüm ile yeniden belirlenmiştir. Ayrıca, kırıma hızının $\left(\mathrm{V}_{\mathrm{r}}\right) 3.2$ km/sn olduğu kabul edilmiştir. Teorik olarak Green fonksiyonları, Kikuchi ve Kanamori (1991) yöntemine göre 0.1 sn örnekleme aralığı ile hesaplanmıştır. Hesaplamalarda hız modeli olarak PREM (Preliminary Reference Earth Model; Dziewonski ve Anderson, 1981) yer modeli kullanılmıştır. Kırılma işlemini daha ayrıntılı belirleyebilmek için fay düzlemi çok sayıda alt-düzleme ve kaynak zaman fonksiyonunu ise çok sayıda üçgen fonksiyona bölünebilir. Ancak model parametrelerinde artış, çözümde duraysızlığa neden olmakta ve böylece verideki çok küçük bir değişim çözümde büyük değişime yol 
açabilmektedir. Daha duraylı çözümler elde edebilmek için, minimum Akaike Bayesian kriterleri $(A B I C)$ kullanılmış, kaymanın zaman ve uzaydaki dağılımına göre yumuşatma işlemi (smoothing) uygulanmıştır. Ters çözüm işlemleri sonucunda, 2017 Chiapas (Meksika) depreminin fay düzlemi üzerindeki kayma dağılımı, kırılmanın zaman içerisindeki davranışı, kırılan alanın boyutları (fay uzunluğu ve genişliği), moment oran fonksiyonu, maksimum ve ortalama yerdeğiştirme miktarları ve gerilme düşümü gibi dinamik deprem parametreleri belirlenmiştir (Çizelge 1).

\section{Sayısal Tsunami Simülasyonları}

$\mathrm{Bu}$ çalışmada Liu vd. (1998) ve Wang (2009) tarafından geliştirilen COMCOT (Cornell Multi-grid Coupled Tsunami Model) algoritması kullanılarak bu deprem için sayısal tsunami simülasyonu gerçekleştirilmiştir. Simülasyonda 30 yay-sn çözünürlüklü GEBCO-BODC (https://www.gebco.net) batimetri verisi kullanılmıştır. Algoritma, küresel koordinatlarda sığ su denklemlerini hesaplayabilmek için kademeli "leap-frog" (sıçrayan kurbağa) sonlu fark şemasını kullanmaktadır. Yöntem, başlangıçtaki dalga yüksekliğinin modellenmesini, tsunami dalga yayılımının ve çeşitli kıyı bölgelerinde maksimum dalga yüksekliklerinin hesaplanmasını kapsamaktadır. Genel olarak, sayısal tsunami simulasyonlarında başlangıç dalga yüksekliğinin, deprem nedeniyle deniz tabanında oluşan deformasyon ile aynı olduğu varsayılmaktadır (Gica vd., 2007; Titov vd., 2005; Okal vd., 2009; YolsalÇevikbilen ve Taymaz, 2012; Ulutaş, 2013; Yolsal-Çevikbilen vd., 2017, 2019). Bu makalede, 08 Eylül 2017 Chiapas-Meksika ( $M_{w}$ 8.2) depreminin deniz tabanında meydana getirdiği çökme ve yükselme miktarları, depremin tekdüze kayma modeli ile oluştuğu varsayılarak, Okada (1985) elastik dislokasyon yaklaşımı ile hesaplanmıştır (Wang, 2009). Deprem dış merkezi, deprem büyüklüğü, fay düzleminin doğrultusu, eğimi ve kayma açısı ve faylanan alanın boyutları ve fay düzlemi üzerinde meydana gelen ortalama yerdeğiştirme miktarı (Çizelge 1) kullanılarak deniz tabanında deprem nedeniyle oluşan düşey yükselim ve çökme miktarları hesaplanmıştır. Bu yaklaşıma göre, belli bir derinlikte bulunan dikdörtgen şekilli fay düzleminde oluşan kayma/kırılma, yarı sonsuz elastik ortamda bir gerilme alanı oluşturarak deprem esnasında deniz tabanında deformasyona neden olur (Mansinha ve Smylie, 1971; Okada, 1985). Kaynak parametrelerinin başlangıç tsunami dalgasına ve tsunami simülasyon sonuçlarına etkileri/katkıları farklıdır ve bu etkiler birçok makalede detaylı olarak tartışılmıştır (Geist, 1999; Yolsal ve Taymaz, 2010). Örneğin, Yolsal ve Taymaz (2010) kırılma oluştuğu anda meydana gelen başlangıç tsunami dalgası yüksekliğine ve kıyılarda hesaplanan dalga genliklerine en fazla etki eden deprem kaynak parametresinin kaynakta boşalan enerjinin miktarı olan sismik moment $\left(M_{0}\right)$ ve dolayısıyla depremin büyüklüğü $\left(M_{w}\right)$ olduğunu önermektedir. Tsunami simülasyon sonuçlarını etkileyen bir diğer önemli parametrenin deprem lokasyonu olduğunu, deprem 
konumuna bağlı olarak, episantır ve çeşitli kıyılar arasındaki uzaklıklar değişeceği için tsunami dalgalarının kıyılara ulaşma süreleri ve genliklerinin de değişim göstereceğini rapor etmişlerdir. Odak mekanizması çözümünün değişmesi durumunda ise tsunami dalgalarının yayılma doğrultuları değişmekte ve dolayısıyla dalgaların kıyılara ulaşma süreleri değişerek farklı mekanizmalar için farklı şekil ve genliklerde yapay tsunami dalgaları elde edilmektedir.

Tsunami simülasyonunda 2 yay-dk ve 0.5 yay-dk hesaplama çözünürlüğüne sahip iki ayrı bölge tanımlanmıştır. Biri diğerini içine alan ve farklı hesaplama çözünürlüklü bu iki bölge için yapılan sayısal simülasyonlarda geçerli olan koordinat sistemi küresel koordinat sistemidir. Okyanus tabanının sürtünme kuvveti simülasyonda hesaba katılmış ve hesaplamalarda Manning katsayısı 0.025 olarak alınmıştır. Her iki bölge için dalga yüksekliği ve kuzey-güney ve doğu-batı yönlü dalga hızı hesaplanmıştır. Tsunami dalga yüksekliği hesaplanırken, 2 yay-dk hesaplama çözünürlüğüne sahip olan bölgede doğrusal sığ su denklemleri, diğer bölgede ise doğrusal olmayan sığ su denklemleri kullanılmıştır. Tsunami dalgalarının okyanus içerisinde 4 saat'lik süre içinde yayılımı belirlenmiş ve simulasyondaki hesaplama zaman aralığı $(\Delta t)$ Courant-Friedrichs-Lewy $(C F L)$ kriterini sağlayacak şekilde 1 sn olarak alınmıştır. İki bölge arasındaki sınır koşulu olarak ise açık (etkisiz) sınır koşulu seçilmiştir. Tsunami dalgalarının okyanus içerisinde yayılımları ve çeşitli kıyılarda hesaplanan yapay tsunami dalgalarının karakteristik özellikleri, kıyı ve açık denizlerde ölçülen ve Gerçek-Zamanlı Derin Deniz Tsunami Belirleme ve Raporlama Şamandıraları (DART) ve kıyılardaki gelgit ölçerler (tide-gauge) tarafından kaydedilen gözlemsel tsunami dalgalarıyla karşılaştırılmıştır (NDBC, 2017; IOC, 2017). Gözlemsel DART kayıtlarında deniz seviyesi değişimi ve zaman bilgileri tespit edildikten sonra, depremin oluş zamanından DART verisindeki değişimin gözlendiği zaman çıkartılmış ve saat formatına dönüştürülmüştür. Bu işlemden sonra üst üste birden fazla kaydedilmiş veriler silinmiştir. Gel-git ölçer verilerinde ise depremin oluş zamanına göre verinin başladığı zaman belirlenmiştir. Daha sonra, tsunami kayıtları örnekleme aralığı 15 sn olacak şekilde tekrar örneklenmiştir. Ayrıca, gel-git etkilerini ve yüksek frekanslı deniz seviyesi değişimlerini gözlemsel tsunami verilerinden atmak için alçak geçişli ve yüksek geçişli Butterworth filtreleme işlemleri uygulanmıştır.

\section{SONUÇLAR}

08 Eylül 2017 Chiapas - Meksika ( $M_{w}$ 8.2) depremine ait kaynak mekanizması çözümü telesismik uzun periyotlu 25 P- ve $6 \mathrm{SH}$ - dalga şeklinin kullanıldığı ters çözüm işlemi ile belirlenmiştir (Çizelge 1 ve Şekil 2). 2017 Chiapas depreminin küçük miktarda doğrultu 
atım bileşenine sahip baskın normal faylanma mekanizması ile meydana geldiği belirlenmiştir. Fay düzleminin doğrultu, eğim ve kayma açıları sırasıyla, $311^{\circ}, 82^{\circ}$ ve $-105^{\circ}$ olarak belirlenmiştir (Çizelge 1).

Çizelge 1. Ters çözüm işlemleri sonucunda 08 Eylül 2017 Chiapas-Meksika $\left(M_{w}\right.$ 8.2) depremine ait olarak belirlenen kaynak mekanizması parametreleri. * ile işaretlenen parametreler USGS-NEIC deprem kataloğundan alınmıştır.

Table 1. Source mechanism parameters of the September 08, 2017 Chiapas-Mexico ( $M_{w}$ 8.2) earthquake obtained by this study. * denotes the parameters taken from USGS-NEIC earthquake catalogue.

\begin{tabular}{|c|c|c|}
\hline & \multicolumn{2}{|c|}{$\begin{array}{c}08 \text { Eylül } 2017 \\
\text { Chiapas (Meksika) depremi }\end{array}$} \\
\hline & $\begin{array}{c}\text { Nokta-Kaynak } \\
\text { İkili-kuvvet çifti }\end{array}$ & $\begin{array}{c}\text { Sonlu-fay } \\
\text { Kayma modeli }\end{array}$ \\
\hline Enlem $\left(\mathbf{K}^{\circ}\right)$ & $15.022^{*}$ & $15.022^{*}$ \\
\hline Boylam (B') & $93.899^{*}$ & $93.899^{*}$ \\
\hline Oluş Zamanı (h:m:s) & 04:49:19* & $04: 49: 19^{*}$ \\
\hline Odak Derinliği (km) & 54 & 54 \\
\hline Doğrultu $\left(\phi,{ }^{\circ}\right)$ & 311 & 311 \\
\hline $\operatorname{Eğim~}\left(\delta,{ }^{\circ}\right)$ & 82 & 82 \\
\hline Kayma açısı $\left(\lambda,{ }^{\circ}\right)$ & -105 & -85.9 \\
\hline $\begin{array}{r}\text { Fay uzunluğu } \\
(\mathrm{L}, \mathbf{k m})\end{array}$ & - & 125 \\
\hline $\begin{array}{r}\text { Fay genişliği } \\
(\mathbf{W}, \mathbf{k m})\end{array}$ & - & 55 \\
\hline $\begin{array}{l}\text { Ortalama yerdeğiştirme }(\mathrm{m}) \\
\text { Maksimum yerdeğ }\end{array}$ & - & $\begin{array}{c}5.2 \\
22.8\end{array}$ \\
\hline$M_{0} \times 10^{21}(\mathrm{Nm})$ & 2.21 & 2.295 \\
\hline $\mathbf{M}_{\mathbf{w}}$ & 8.2 & 8.2 \\
\hline
\end{tabular}

Deprem odak derinliği sığ olup, 54 km olarak saptanmıştır. Kaynak zaman fonksiyonu, odakta başlayan basit yapılı bir kırılmanın meydana geldiğini, enerji boşalımının büyük ölçüde ilk 60-70 sn içerisinde gerçekleştiğini ve sismik moment değerinin $\left(M_{0}\right) 2.21 \times 10^{21}$ $\mathrm{Nm}$ olduğunu göstermektedir (Şekil 2). Yakın alan ve telesismik uzaklıklarda yer alan istasyonlarda kaydedilen P- dalgası ilk hareket yönlerinin odak küresi üzerindeki azimutal dağılımları ters çözüm sonucu ile oldukça uyumludur. Örneğin, KB-GD uzanımlı fay düzlemine çok yakın yerde bulunan ve yukarı doğru P- dalgası ilk hareket yönünü gösteren deprem kaydına sahip $\operatorname{WUAZ}\left(\Delta=25.79^{\circ}\right)$ istasyonu odak mekanizması çözümü ile uyumlu olarak sıkışma bölgesinde, aşağı doğru P- dalgası ilk hareket yönünü gösteren $\operatorname{KDAK}\left(\Delta=60.93^{\circ}\right)$ istasyonu ise genişleme bölgesinde yer almaktadır (Şekil 3). Kaynak mekanizması parametrelerinin belirlenmesi esnasında yapılan hata miktarlarının ise yaklaşık olarak $\pm 5-10^{\circ}$ olduğu saptanmıştır. 
08 EYLÜL 2017 - CHIAPAS - MEKSIKA (Mw = 8.2)

NP1: $311^{\circ} / 82^{\circ} /-105^{\circ} \mathrm{NP2}: 194^{\circ} / 17^{\circ} /-29^{\circ} \mathrm{h}=54 \mathrm{~km} \quad \mathrm{Mo}=2.21 \mathrm{E} 21 \mathrm{Nm}$
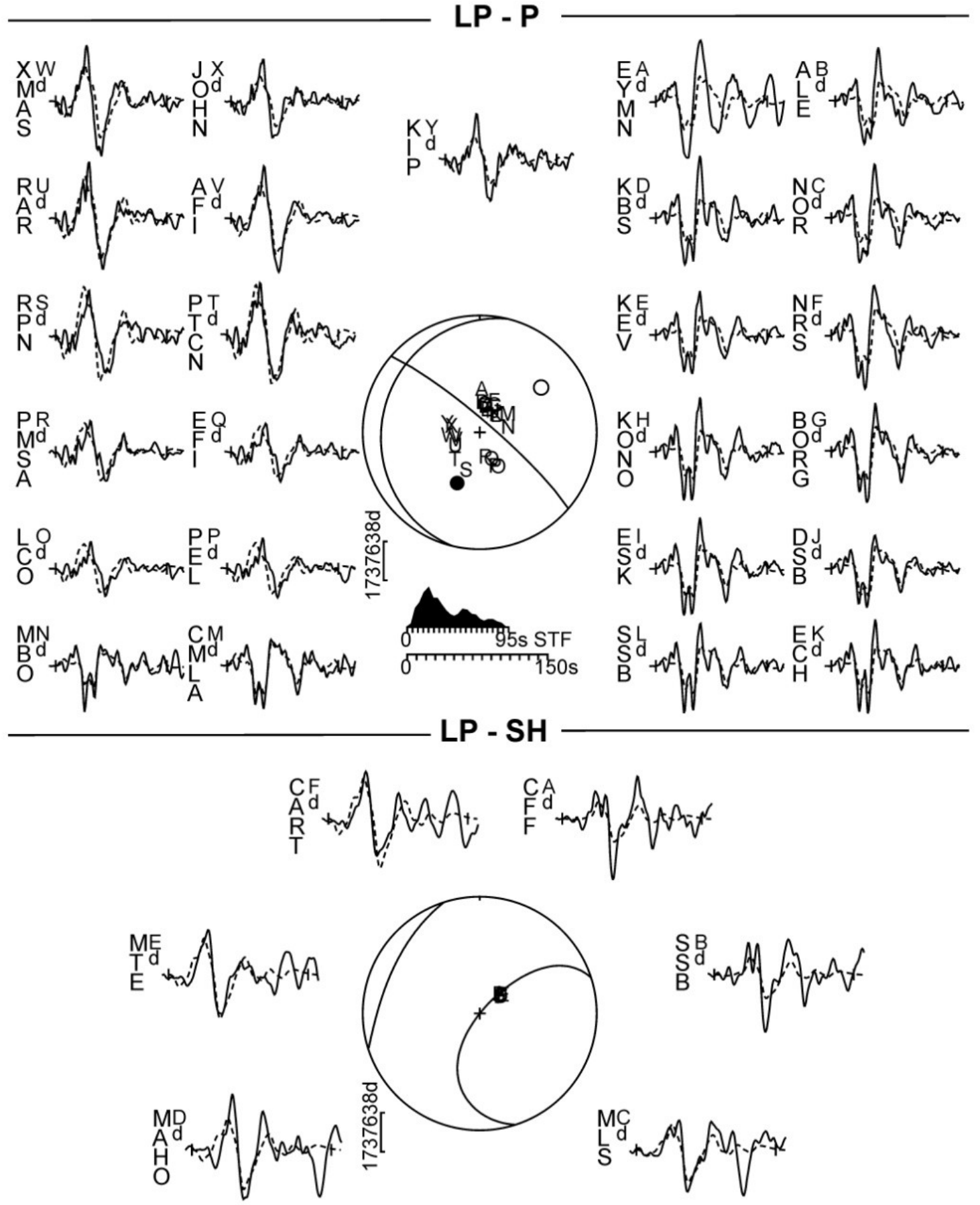

Şekil 2. 08 Eylül 2017 Chiapas-Meksika $\left(M_{w} 8.2\right)$ depremine ait olarak telesismik uzun periyotlu 25 P- ve $6 \mathrm{SH}$ - dalga şeklinin modellenmesiyle belirlenen odak mekanizması çözümü. Her iki düğüm düzlemi için saptanan doğrultu, eğim ve kayma açıları, deprem odak derinliği, sismik moment değeri şeklin üzerinde özetlenmiştir. Kaynak zaman fonksiyonu (STF) şeklin ortasında P- odak küresinin altında gösterilmiştir. P- ve SH- odak küreleri, alt yarımküre projeksiyon ağı ile çizilmiştir. P- ve T- eksenleri sırasıyla dolu ve boş daireler ile gösterilmiştir (detaylar için bkz. Meriç, 2019).

Figure 2. Minimum misfit solution of the September 08, 2017 Chiapas-Mexico earthquake $\left(M_{w} 8.2\right)$ obtained by using teleseismic long period $25 \mathrm{P}$ - and $6 \mathrm{SH}$ - waveforms. Strike, dip and rake angles of nodal planes, focal depth and seismic moment of this earthquake is given on header. The source time function (STF) is also given in the middle of figure, and beneath it is shown the time scale used for the waveforms. Focal spheres are shown with $P$ (top) and SH (bottom) nodal planes in lower hemisphere projections. $P$ - and $T$ - axes are marked by solid and open circles, respectively (see for details Meriç, 2019). 


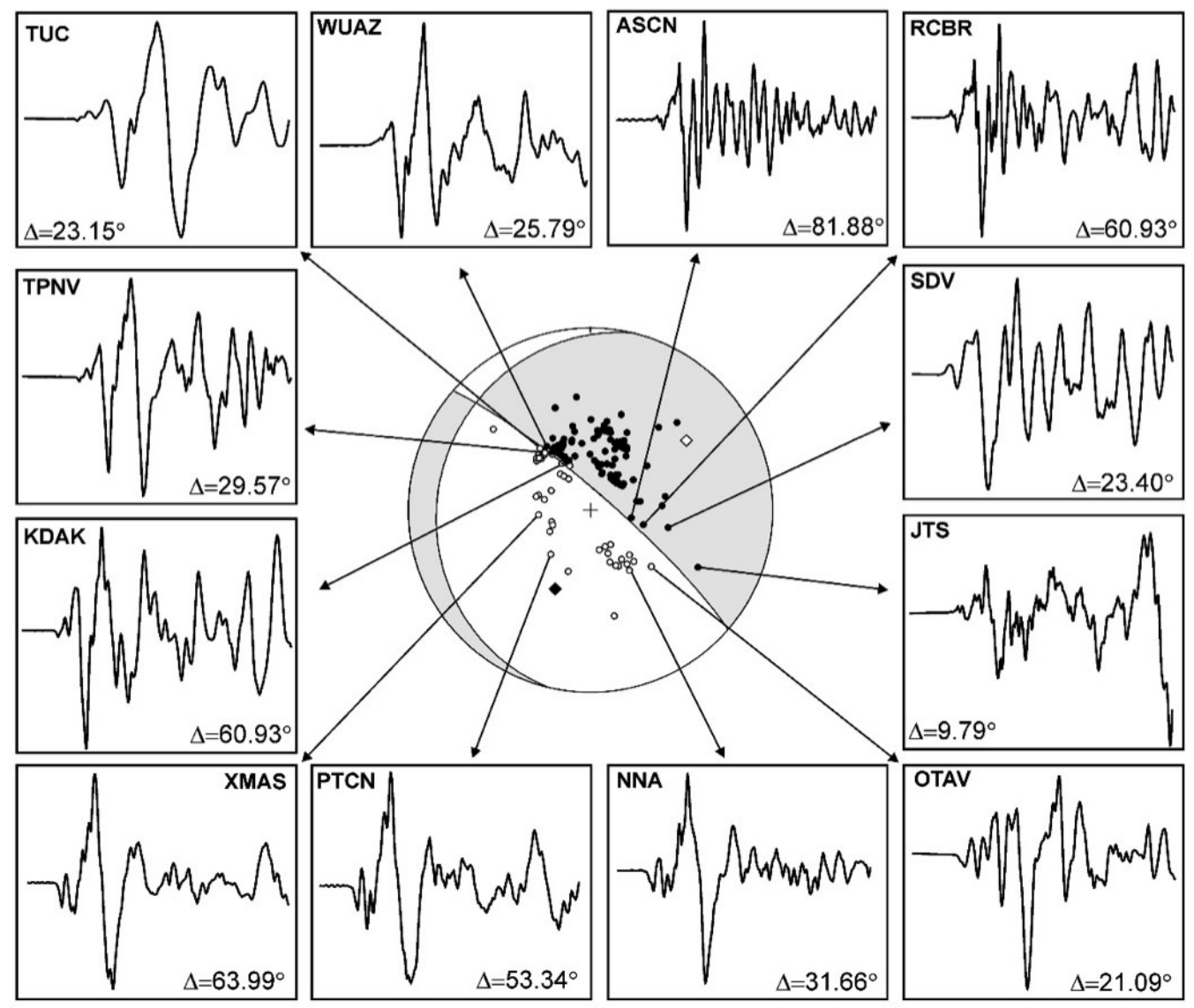

Şekil 3. 08 Eylül 2017 Chiapas-Meksika $\left(M_{w}\right.$ 8.2) depremine ait olarak, yakın ve uzak alanda yer alan deprem kayıt istasyonları tarafından kaydedilen P- dalgası ilk hareket yönlerinin azimut açısına bağlı olarak dağılımı. Yukarı ve aşağı yönlü P- dalgası ilk hareket yönleri, sırasıyla siyah ve beyaz daireler ile gösterilmiştir (detaylar için bkz. Meriç, 2019).

Figure 3. Azimuthal distributions of P-wave first motion polarities of 08 September 2017 ChiapasMexico earthquake recorded at near-field and teleseismic seismic stations. Up and down polarities are shown with black and open circles, respectively (see for details Meriç, 2019).

Fay düzlemi üzerinde gerçekleşen kayma/yırtılma dağılımını belirleyebilmek için yapılan ters çözüm işleminde ise 39 adet telesismik genişbantlı P- dalga şekli kullanılmıştır (Şekil 4 ve 5). Depremin meydana geldiği bölgenin genel tektonik yapısı gözönünde bulundurularak, $82^{\circ}$ eğim açısına sahip KB-GD uzanımlı düzlemin fay düzlemi olduğu kabul edilmiştir. Fay düzlemi $5 \mathrm{~km}$ x $5 \mathrm{~km}$ grid boyutunda 24 x 10 adet alt-faya bölünmüştür. Kaynak zaman fonksiyonu 2 sn yükselme zamanına sahip 15 adet üçgen fonksiyondan oluşmaktadır.

Kayma dağılımı modelinin belirlenmesi için, farklı boyutlarda ve sayılarda alt-faya bölünmüş fay düzlemi ile 14 adet ters çözüm yapılmıştır, bunlardan en küçük varyans değerine sahip, gözlemsel ve sentetik dalga şekilleri arasında en iyi uyumu veren model, sonuç modeli olarak seçilmiştir. Kayma modeli, fay düzlemi üzerinde gerçekleşen kırılmanın yaklaşık 60 sn sürdüğünü ve telesismik $\mathrm{P}$ - ve SH- dalga şekli modelleme sonucu ile uyumlu olarak basit yapılı olduğunu göstermektedir (Şekil 2 ve 4). 125 km fay 
uzunluğuna ve $55 \mathrm{~km}$ fay genişliğine sahip olarak belirlenen KB-GD uzanımlı fay düzlemi üzerinde meydana gelen maksimum yerdeğiştirme miktarının ( $D_{\text {maks }}$ ) ise $22.10 \mathrm{~m}$ olduğu saptanmıştır. Belirlenen fay boyutları, Wells ve Coppersmith (1994) ampirik bağıntıları ve depremin sismik momenti $\left(\mathrm{M}_{\mathrm{O}}\right) 2.295 \times 10^{21} \mathrm{Nm}$ kullanılarak bulunan değerler (fay uzunluğu: 123 km; fay genişliği: 53 km, $D_{\text {maks: }} 25 \mathrm{~m}$ ) ile uyumludur (Çizelge 1 ve Şekil 4).

08 Eylül 2017 Chiapas - Meksika ( $\mathrm{M}_{\mathrm{w}}$ 8.2)

NP1: $311^{\circ} / 82^{\circ} /-86^{\circ}$ NP2: $104^{\circ} / 9^{\circ} / 116^{\circ}$ Sismik Moment $(\mathrm{Mo})=2.295 \times 10^{21} \mathrm{Nm}$ Odak Derinliği $=54 \mathrm{~km} \mathrm{Vr}_{\text {max }}=3.2(\mathrm{~km} / \mathrm{sec})$
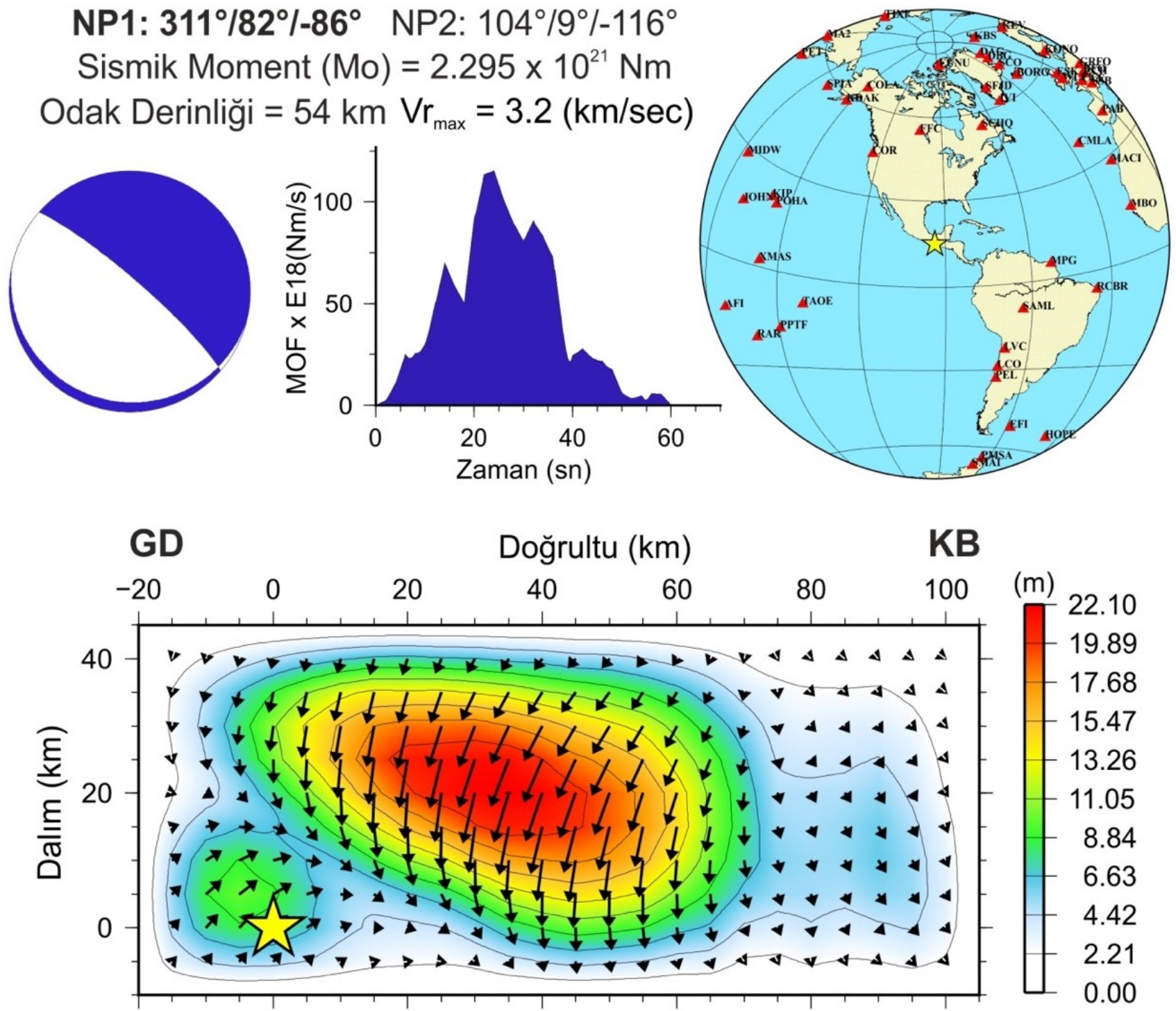

Şekil 4. 08 Eylül 2017 Chiapas-Meksika depremine $\left(M_{w} 8.2\right)$ ait olarak belirlenen fay düzlemi üzerindeki sonlu-fay kayma dağılımı modeli. Odak mekanizması, kaynak zaman fonksiyonu ve ters çözümde kullanılan telesismik istasyonların dağılımları gösterilmiştir (detaylar için bkz. Meriç, 2019).

Figure 4. Finite-fault slip distribution model of the September 08, 2017 Chiapas-Mexico (Mw 8.2) earthquake determined by slip inversion. Focal mechanism, source time function and teleseismic station distribution used in inversion are also provided (see for details Meriç, 2019). 
RCBRBHZ

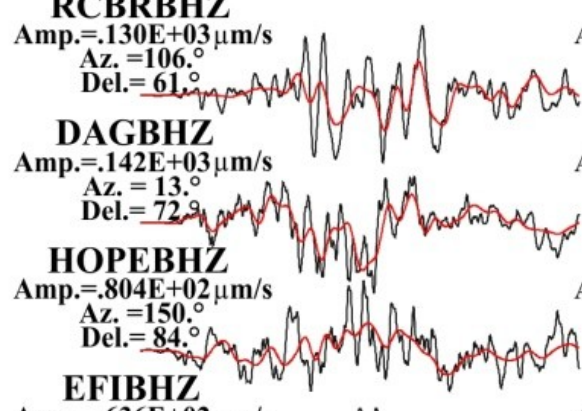

KBSBHZ

Amp. $=.161 \mathrm{E}+03 \mu \mathrm{m} / \mathrm{s}$ Az. $=11$
SAMLBHZ

Amp. $=.110 \mathrm{E}+03 \mu \mathrm{m} / \mathrm{s}$

EUNUBHZ

Amp. $=.186 \mathrm{E}+03 \mu \mathrm{m} / \mathrm{s}$

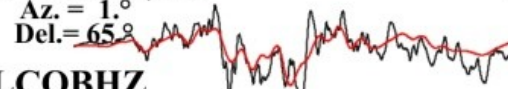

Amp. $=.934 \mathrm{E}+02 \mu \mathrm{m} / \mathrm{s}$ Az. $=153$.
Del. $=490^{\circ}$

DBGBHZ

Amp. $=.636 \mathrm{E}+02 \mu \mathrm{m} / \mathrm{s}$ $A z=158$. Del. $=73{ }^{\circ}$

SMAIBHZ

Amp. $=.670 \mathrm{E}+02 \mu \mathrm{m} / \mathrm{s}$ $\mathrm{Az}^{2}=170$.

Del. $=85$.

SCOBHZ

Amp. $=.164 \mathrm{E}+03 \mu \mathrm{m} / \mathrm{s}$ $\mathrm{Az}=\mathbf{2 0} 0^{\circ}$

Amp. $=.164 \mathrm{E}+03 \mu \mathrm{m} / \mathrm{s}$

RARBHZ

Amp. $=.183 \mathrm{E}+03 \mu \mathrm{m} / \mathrm{s}$

$\mathrm{Az}=242 .{ }^{\circ}$

AFIBHZ

$A \mathrm{mp}=.972 \mathrm{E}+02 \mu \mathrm{m} / \mathrm{s}$

Az. $=\mathbf{2 5 3}$.

Del. $=82.04$

Amp. $=.142 \mathrm{E}+03 \mu \mathrm{m} / \mathrm{s}$ $\mathrm{Az} .=283$.

Dei. $=72$.

MIDWBHZ

Amp. $=.800 \mathrm{E}+02 \mu \mathrm{m} / \mathrm{s}$ $\mathrm{Az}=296$.

Del. $=78$.

CORBHZ

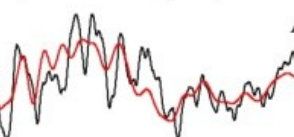

Amp. $=.118 \mathrm{E}+03 \mu \mathrm{m} / \mathrm{s}$

Az. $=16$.
Del. $=71^{\circ}$

KEVBHZ

$\begin{aligned} & \text { Amp. }=.991 \mathrm{E}+02 \\ & \text { Azz }=17 .{ }^{\circ} \\ & \text { Del. }=86^{\circ}\end{aligned}$

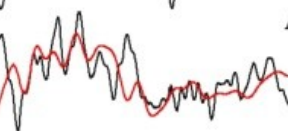

SCHOBHZ

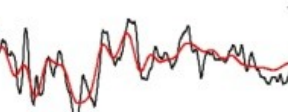

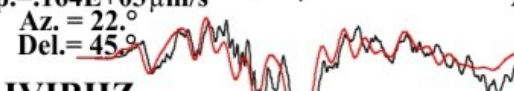

IVIBHZ

Amp. $=.187 \mathrm{E}+03 \mu \mathrm{m} / \mathrm{s}$


$\begin{gathered}\mathrm{Az} \\ \mathrm{De}\end{gathered}=\mathbf{2}=\mathbf{5 6} .^{\circ} \mathrm{M} / \mathrm{M}$

\section{BORGBHZ}

Amp. $=.211 \mathrm{E}+03 \mu \mathrm{m} / \mathrm{s}$

$\mathrm{Az}=26$.



POHABHZ

Amp. $=.156 \mathrm{E}+03 \mu \mathrm{m} / \mathrm{s}$

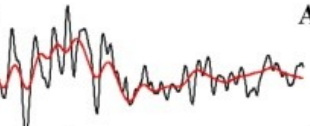

$A z=284$.

KONOBHZ

Amp. $=.193 E+03$

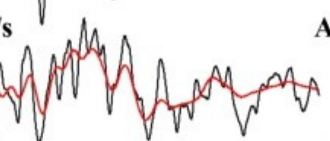
Az. $=30$.

SPIABHZ

Amp. $=.142 \mathrm{E}+03 \mu \mathrm{m} / \mathrm{s}$

Del. $=39$.
Az. $=326$.

Amp. $=.746 \mathrm{E}+02 \mu \mathrm{m} / \mathrm{s}$

MA2BHZ

Amp. $=.387 \mathrm{E}+02 \mu \mathrm{m} / \mathrm{s}$ Az. $=333$. Del. $=89.9 \mathrm{~A}$

FFCBHZ

Amp. $=.189 \mathrm{E}+03 \mu \mathrm{m} / \mathrm{s}$

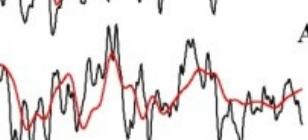

Az. $=3260^{\circ}$
Del. $=70.9 \mathrm{~A}$

COLABHZ

Amp. $=.787 \mathrm{E}+02 \mu \mathrm{m} / \mathrm{s}$

Az. $=337$.

\section{ESKBHZ}

Amp. $=.223 \mathrm{E}+03 \mu \mathrm{m} / \mathrm{s}$



\section{GRFOBHZ}

Amp. $=$,

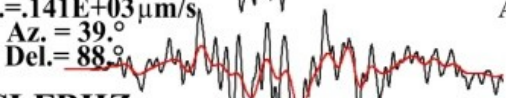
CLFBHZ

Amp. $=.253 \mathrm{E}+03 \mu \mathrm{m} / \mathrm{s}$

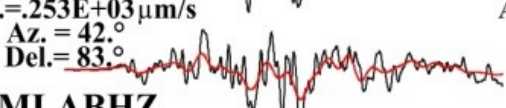

CMLABHZ

Amp. $=.135 \mathrm{E}+03 \mu \mathrm{m} / \mathrm{s}$



Amp. $=.647 \mathrm{E}+02 \mu \mathrm{m} / \mathrm{s}$

Az $=990^{\circ}$
Dei.

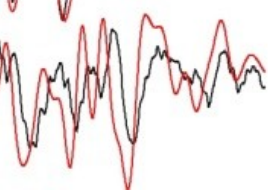

\section{BFOBHZ}

Amp. $=.132 \mathrm{E}+03 \mu \mathrm{m} / \mathrm{s}$ $A z$
Dei $=87^{\circ}$

SSBBHZ

Amp. $=.125 \mathrm{E}+03 \mu \mathrm{m} / \mathrm{s}$ $\mathrm{Az}^{\circ}=44{ }^{\circ}$

Amp. $=.118 \mathrm{E}+03 \mu \mathrm{m} / \mathrm{s}$

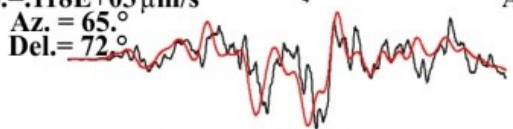

Zaman (sn)

$\begin{array}{lllll}0 & 20 & 40 & 60 & 80\end{array}$
MACIBHZ

LVCBHZ

Amp. $=.911 \mathrm{E}+02 \mu \mathrm{m} / \mathrm{s}$

Az. $=147{ }^{\circ}$

Del. $=45$.

PELBHZ

Amp. $=.818 \mathrm{E}+02 \mu \mathrm{m} / \mathrm{s}$

Amp. $=.739 \mathrm{E}+02 \mu \mathrm{m} / \mathrm{s}$ SFJDBHZ

Amp. $=.178 \mathrm{E}+03 \mu$

Amp. $=.184 \mathrm{E}+03 \mu \mathrm{m} / \mathrm{s}$ Az. $=2411^{\circ}$

TAOEBHZ

Amp. $=.214 \mathrm{E}+03 \mu \mathrm{m} / \mathrm{s}$

$A z .=246 .^{\circ}$

Amp. $=.182 \mathrm{E}+03 \mu \mathrm{m} / \mathrm{s}$

$\begin{gathered}=.182 \mathrm{E}+03 \\ \mathrm{Az} .\end{gathered}=265 .^{\circ}$

Amp. $=.121 \mathrm{E}+03 \mu \mathrm{m} / \mathrm{s}$

PETBHZ

PETBHZ

Amp. $=.391 \mathrm{E}+02 \mu \mathrm{m} / \mathrm{s}$

KDAKBHZ

Amp. $=.792 \mathrm{E}+02 \mu \mathrm{m} / \mathrm{s}$ Az. $=329 .^{\circ}$

TIXIBHZ

Amp. $=.476 E+02 \mu \mathrm{m} / \mathrm{s}$


$\mathrm{Az} .=348$.

WLF1BHZ

Amp. $=.325 \mathrm{E}+03 \mu \mathrm{m} / \mathrm{s}$

PMSABHZ

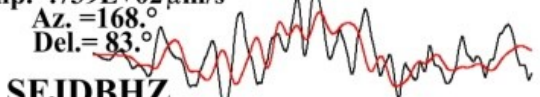

Dei. $=59$.
PPTFBHZ

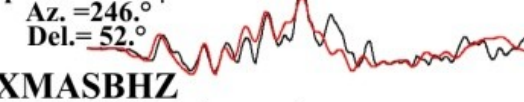

КIPBHZ

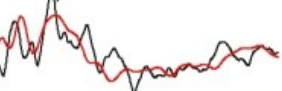
moon 
Son aşamada, 2017 Chiapas depremi $\left(M_{w}\right.$ 8.2) ve tsunamisine ait matematiksel tsunami simülasyonu gerçekleştirilmiştir. Yapılan sayısal simülasyonda, KB-DG uzanımlı fay düzlemi (doğrultu: $311^{\circ}$, eğim: $82^{\circ}$, kayma: $-105^{\circ}$ ) üzerinde tekdüze kayma dağılımı (fay uzunluğu: 125 km, fay genişliği: 55 km) olduğu varsayılmıştır. Aki ve Richards (1980) bağıntısı $\left(M_{o}=\mu A D_{\text {ort }}\right)$ ile fay düzlemi üzerinde meydana gelen ortalama kayma miktarı $\left(D_{\text {ort }}=5.2 \mathrm{~m}\right)$ simülasyonda kullanılan bir diğer giriş parametresidir. Bu deprem için Adriano vd. (2018) tarafından önerildiği şekilde katılık (rijidite) değeri $(\mu), 7 \times 10^{11} \mathrm{dyn} / \mathrm{cm}^{2}$ olarak alınmıştır. Deprem oluştuğu anda meydana gelen başlangıç tsunami dalgasının çökme bölgesi yüksekliği $-1.172 \mathrm{~m}$, tepe bölgesi yüksekliği ise $0.791 \mathrm{~m}$ olarak hesaplanmıştır. Hesaplanan çökme miktarı yükselme miktarından daha fazladır; bu da depremin kaynak mekanizması çözümü (örn., normal faylanma) ile uyumludur. Oluşan tsunami dalgalarının 4 saatlik süre boyunca okyanus içerisinde ilerleyişi modellenmiş ve dalgaların çeşitli kıyılara varış zamanları, dalga şekilleri ve genlikleri belirlenmiştir (Şekil 6 ve 7).

Çeşitli kıyılar için hesaplanan tsunami dalgalarının genlik, şekil ve zaman özellikleri, 3 adet okyanus içi DART şamandıraları (örn., DART-32411, DART-32413 and DART-43413) ve 1 adet gel-git ölçer (örn., Huatulco) tarafından kaydedilen gerçek-zamanlı tsunami kayıtları ile karşılaştırılmıştır (Çizelge 2). Genel olarak bakıldığında, kayıtçılara ulaşan ilk tsunami dalgasının varış zamanının ve dalga şekillerinin özellikle okyanus içi DART kayıtları ile uyumlu olduğu görülmektedir. Ancak Huatulco gel-git ölçer istasyonu tarafından kaydedilen tsunami dalgası ile hesaplanan dalga arasında belirgin bir varış zamanı farkı gözlenmektedir (Şekil 7).

Çizelge 2. Gerçek-zamanlı tsunami verilerinin kaydedildiği DART şamandıraları ve gelgit ölçer istasyonlarının koordinatları (bkz. NDBC, 2017; IOC, 2017).

Table 2. Coordinates of DART buoys and tide-gauge stations where real-time tsunami data are recorded (see NDBC, 2017; IOC, 2017).

\begin{tabular}{ccc}
\hline İstasyon adı & Enlem $\left({ }^{\circ} \mathrm{K}\right)$ & Boylam $\left({ }^{\circ} \mathrm{D}\right)$ \\
\hline DART 32411 & 4.953 & -90.880 \\
DART 32413 & -7.406 & -93.517 \\
DART 43413 & 11.012 & -100.083 \\
Huatulco & 15.7500 & -96.1168 \\
\hline
\end{tabular}




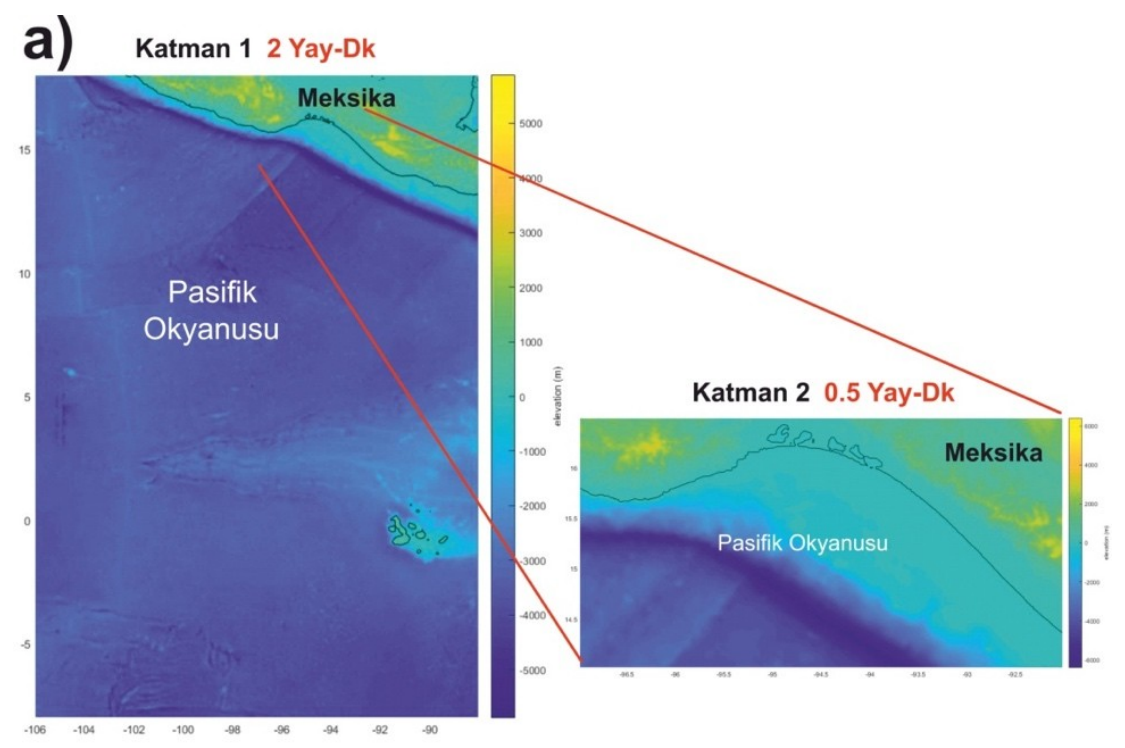

b)

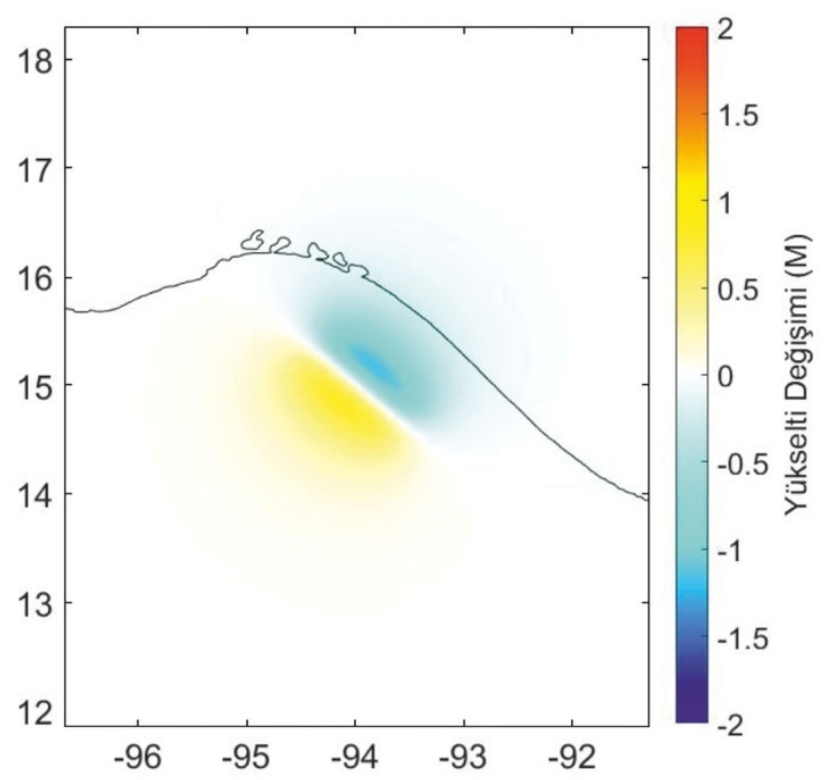

Şekil 6. (a) Sayısal tsunami simülasyonunda tanımlanan 2 yay-dk ve 0.5 yay-dk hesaplama çözünürlüğüne sahip katmanlar, (b) Tekdüze kayma modeline dayalı olarak gerçekleştirilen simülasyonda hesaplanan başlangıç tsunami dalga yüksekliği. Başlangıç dalgası tepe noktası yüksekliği $0.791 \mathrm{~m}$, çökme noktası yüksekliği ise $-1.172 \mathrm{~m}$ olarak hesaplanmıştır.

Figure 6. (a) Computational layers with 2 arc-min and 0.5 arc-min used for numerical tsunami simulations, (b) Initial tsunami wave calculated using the uniform slip model of the 2017 Chiapas (Mexico) earthquake in tsunami simulation. The crest and through of the initial wave is found as $0.791 \mathrm{~m}$, and $-1.172 \mathrm{~m}$, respectively.

\section{TARTIŞMA}

Deprem verilerinin ters çözüm işlemleri ile modellenmeleri sonucunda elde edilen deprem kaynak mekanizması parametrelerinin sayısal tsunami simülasyonlarda giriş parametresi olarak kullanılmasının gerekliliği bilinmektedir. Bu çalışmada yapılan ters çözüm işlemleri sonucunda, 08 Eylül 2017 Chiapas-Meksika ( $M_{w}$ 8.2) depreminin normal faylanma mekanizması ile 54 km odak derinliğinde meydana geldiği belirlenmiştir (Şekil 2). Yıkıcı olan bu deprem Orta Amerika Hendeği boyunca olan dalma batma zonunda sismik boşluk 
olarak nitelendirilen bir bölgede meydana gelmiştir, ancak bindirme mekanizması ile oluşmadığı için bu depremin bölgedeki mevcut gerilmeyi boşaltmadığı çeşitli Coulomb gerilme analizleriyle saptanmıştır (örn., Heidarzadeh vd., 2018; Spagnotto vd., 2018). Bu çalışmada telesismik P- dalga şekillerinin ters çözümü ile elde edilen sonlu-fay kayma dağılımı modeli, fay düzlemi üzerinde gerçekleşen kırılmanın odakta başladığını, eğim doğrultusu boyunca deniz tabanına yakın bir derinliğe kadar ilerlediğini, basit yapılı olduğunu ve maksimum yerdeğiştirmenin ( $D_{\text {maks: }} 22.10 \mathrm{~m}$ ) deprem episantır noktasının KB'sında yaklaşık 25 km derinlikte meydana geldiğini göstermektedir Kırılma süresi ise 6070 sn olarak belirlenmiştir (Şekil 2 ve 4). Benzer şekilde, Heidarzadeh vd. (2018) kırılma süresini 59.5 sn, Jiménez (2018) ise 75 sn olarak rapor etmiştir. İleride yapılacak çalışmalar ile 2017 Chiapas (Meksika) depreminin fay düzlemi üzerinde meydana gelen kayma/yırtılma dağılımının, farklı veri setlerinin (örn., yakın alan ivme kayıtları, tsunami ve GPS verileri vb) ters çözüm işlemlerine eklenmesiyle daha detaylı olarak belirlenebilmesi mümkündür.
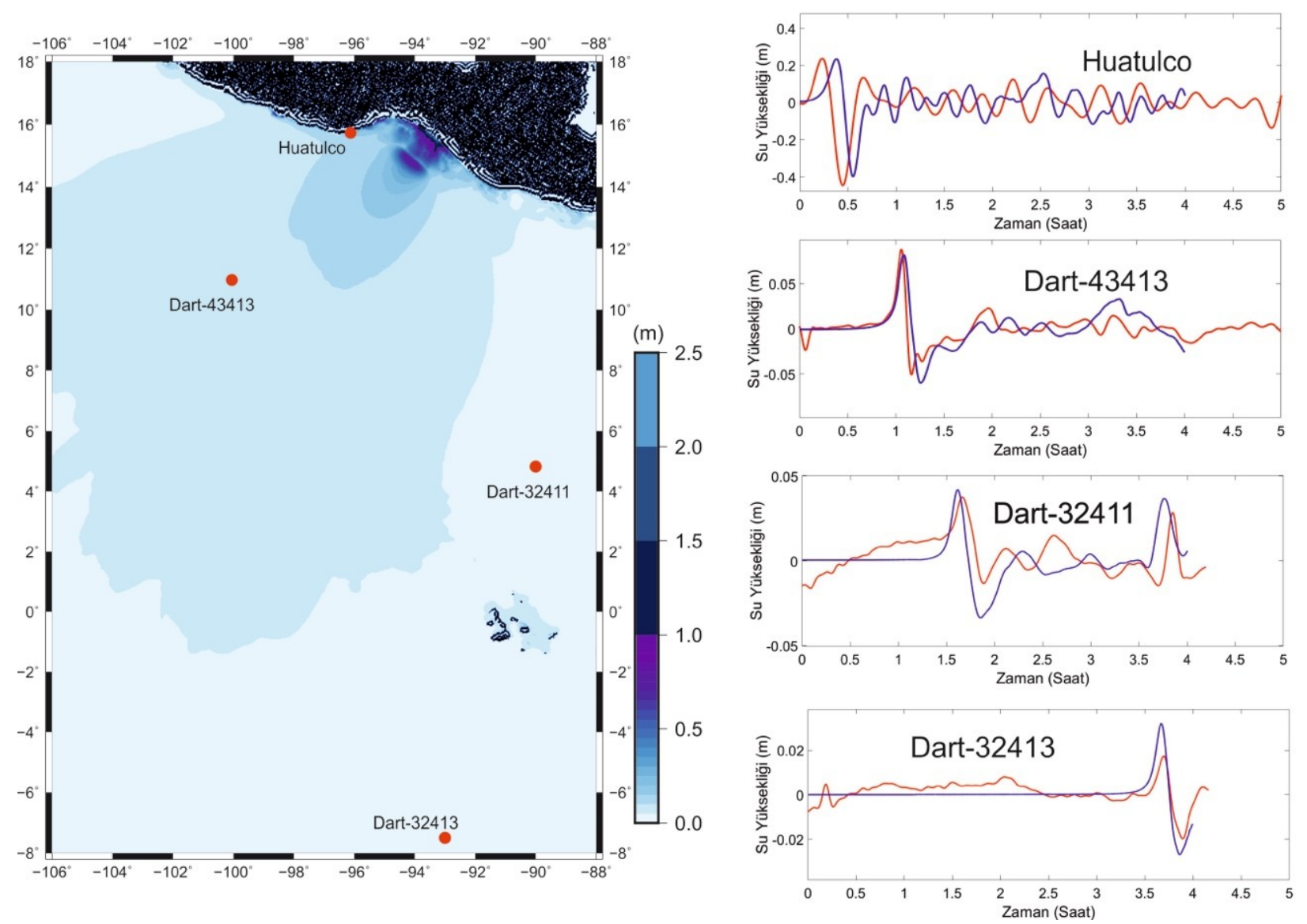

Şekil 7. 08 Eylül 2017 Chiapas-Meksika depremi tsunamisi simülasyonunda 2 yay-dk hesaplama çözünürlüğü ile hesaplanan maksimum tsunami dalga yüksekliklerinin dağılımı ve hesaplanan (mavi) ve gözlemsel (kırmızı) tsunami dalgalarının karşılaştırılması. Kırmızı daireler DART şamandıraları ve gelgit ölçerin konumunu göstermektedir.

Figure 7. Computed maximum tsunami wave heights for the September 08, 2017 Chiapas-Mexico earthquake with a computational grid of 2 arcmin, and comparison of the real-time tsunami data (red) recorded by DART buoys and tide gauges with the calculated waveforms (blue). Red dotes indicate the locations of the DART buoys and tide gauge station. 
Son aşamada ise, fay düzlemi boyunca kayma dağıımının tekdüze (homojen) olduğu varsayımına dayalı olarak gerçekleştirilen sayısal tsunami simülasyonunda 2017 Chiapas (Meksika) depremine ait kaynak mekanizması parametreleri (Çizelge 1) giriş parametresi olarak kullanılmış ve Okada (1985) elastik dislokasyon yaklaşımına göre başlangıç tsunami dalgası hesaplanmıştır (Şekil 6b). Odak derinliğinde başlayıp yüzeye ulaşmayan kaymaların elastik dislokasyon yaklaşımına göre okyanus tabanında oluşturduğu düşey yönlü çökme ve yükselme miktarları hesaplanabilir. Ayrıca, farklı dislokasyon modellerine dayalı olarak da tsunami oluşumu ve tsunami dalga ilerleyişi modellenebilmektedir. Örneğin, doğrultu atımlı faylanmalarda fay düzlemi boyunca yatay yerdeğiştirmeler meydana gelmesine rağmen deniz tabanında düşey yerdeğiştirmelerin oluşabileceği ve bunun da tsunami oluşumuna neden olabileceğini gösteren çeşitli çalışmalar bulunmaktadır (örn., Geist ve Dmowska, 1999; Geist ve Oglesby, 2014; Yolsal-Çevikbilen vd., 2017). Deprem nedeniyle oluşan tsunami dalgalarının kaynaktan başlayarak 4 saatlik süre boyunca Pasifik Okyanusu'nda ilerleyişi modellenmiştir. Gerçek zamanlı tsunami kayıtları ile yapılan karşılaştırmalar sonucunda, okyanus içerisinde yer alan DART şamandıralarının kaydettiği tsunami dalgalarının yeterli düzeyde modellenebildiği, ancak yapay ve gözlemsel tsunami dalgalarında genlik ve zaman bakımından en belirgin uyumsuzluğun yakın alanda yeralan gel-git ölçer kaydında (bkz. Huatulca gel-git ölçer kaydı; Şekil 7) gözlendiği saptanmıştır. Bu uyumsuzluğun, sayısal simülasyonda kullanılan 30 yay-sn çözünürlüklü GEBCO-BODC batimetri verisinin nispeten düşük çözünürlüklü olması ve özellikle yakın kıyı detaylarını tam olarak gösterememesinden kaynaklandığı düşünülmektedir. Özellikle kıyılarda bulunan gel-git ölçer kayıtlarının deniz içi ve kıyı batimetri yapısından oldukça fazla etkilendiği ve bu nedenle yakın alanda yer alan bölgeler için yapılan hesaplamalarda daha yüksek çözünürlüklü batimetri verisinin kullanılmasının daha iyi sonuçlar verdiği birçok çalışmada örnekler ile gösterilerek vurgulanmaktadır (örn., Satake, 1988; Mofjeld vd., 2001; Yolsal vd., 2007; Tang vd., 2008; Gusman vd., 2014; Adriano vd., 2018; Chacón-Barrantes, 2018). Ayrıca, güncel çalışmalar sayısal tsunami simülasyonlarında sonlu-fay kayma/yırtılma dağılımının kullanılmasının gözlemsel ve hesaplanan tsunami dalgaları arasındaki uyumun artmasında etkili olabileceğini göstermektedir (Ulutaş, 2013; Yolsal-Çevikbilen vd., 2019). Örneğin, Yolsal-Çevikbilen vd. (2019), 28 Ekim 2012 Haida Gwaii - Kanada $\left(M_{w} 7.7\right)$ ve 16 Eylül 2015 Illapel - Şili $\left(M_{w}\right.$ 8.3) depremlerine ait homojen ve homojen olmayan kayma dağılımı modellerini kullanarak Pasifik Okyanusu içinde ve çeşitli kıyılarda tsunami dalga yüksekliklerini hesaplamış, fay düzlemi üzerinde meydana gelen heterojen kayma dağılımına dayalı olarak yapılan simülasyon sonuçlarının tsunami dalga özelliklerinin daha iyi belirlenmesinde etkili olduğunu rapor etmişlerdir. Bu nedenle özellikle kıyılarda gel-git ölçerler tarafından kaydedilen tsunami dalgalarının modellenebilmesi için yapılacak olan ileriki simülasyon 
çalışmalarında yüksek çözünürlüklü batimetri verisinin ve tekdüze olmayan sonlu-fay kayma dağılımı modelinin kullanılmasının gerekliliği bu çalışma ile de gösterilmiştir.

\section{KATKI BELIRTME}

Bu çalışma H.T. Meriç'in yüksek lisans tez çalışmasının (Meriç, 2019) bir bölümünü içermektedir. Çalışmanın yapılmasındaki desteklerinden dolayı Türkiye Bilimler Akademisi - Üstün Başarılı Genç Bilim İnsanı Ödülleri Programı'na (TÜBA-GEBIPP), İstanbul Teknik Üniversitesi - Bilimsel Araştırma Projeleri Birimi'ne (İTÜ-BAP) ve Türkiye Bilimsel ve Teknolojik Araştırma Kurumu'na (TÜBITAK) teşekkür ederiz. Çalışmada, Uluslararası Sayısal Sismograf Ağı (FDSN) ve Küresel Sayısal Sismograf Ağı (GDSN) istasyonları tarafından kaydedilen telesismik deprem kayıtları, IRIS-DMC web sayfasından (http://ds.iris.edu/wilber3) alınmıştır. Deprem verilerinin ters çözüme hazırlanması işlemleri SAC2000 program paketi (Goldstein vd., 2003; Goldstein ve Snoke, 2005) ile, haritaların hazırlanması ise haritalama programı GMT (The Generic Mapping Tools; Wessel ve Smith, 1998) ile yapılmıştır. Tsunami kayıtları "www.ioc-sealevelmonitoring.org" ve "www.ndbc.noaa.gov/dart.shtml" kaynaklarından alınmıştır. Ayrıca, sonlu-fay kayma dağılımı modelinin belirlenmesinde kullanılan ters çözüm programı için Yuji Yagi'ye (Tsukuba Üniversitesi, Japonya), sayısal tsunami simülasyonunda kullanılan COMCOT (Cornell Multi-grid Coupled Tsunami Model) algoritması için ise P.L.-F. Liu (Cornell Üniversitesi, ABD) ve Xiaoming Wang'a (Jeoloji ve Nükleer Bilim Enstitüsü, Yeni Zelanda) teşekkür ederiz.

\section{KAYNAKLAR}

Adriano, B., Fujii, Y., Koshimura, S., Mas, E., Ruiz-Angulo, A. and Estrada, M., 2018. Tsunami source inversion using tide gauge and DART tsunami waveforms of the $2017 M_{w} 8.2$ Mexico earthquake. Pure and Applied Geophysics, 175 (1), 35-48.

Aki, K. and Richards, P., 1980. Quantitative seismology: theory and methods. W.H. Freeman and Co., New York.

Ambraseys, N.N. 1962. Data for the investigation of the seismic sea waves in the Eastern Mediterranean. Bulletin of the Seismological Society of America, 52, 895-913.

Ammon, C.J., Lay, T., Kanamori, H. and Cleveland, M., 2011. A rupture model of the 2011 off the Pacific coast of Tohoku Earthquake. Earth, Planets and Space, 63, 693-696.

Antonopoulos, J. 1980. Data from investigation on seismic sea-waves events in the Eastern Mediterranean from the birth of Christ to 1980 AD (6 parts). Annali di Geofisica, 33, 141-248. 
Basili, R., Tiberti, M. M., Kastelic, V., Romano, F., Piatanesi, A., Selva, J. and Lorito, S., 2013. Integrating geologic fault data into tsunami hazard studies. Natural Hazards and Earth System Sciences, 13, 1025-1050.

Bohnoff, M., Hajes, H.-P. and Meier, T., 2005. Deformation and stress regimes in the Hellenic subduction zone from focal Mechanisms. Journal of Seismology, 9, 341366.

Chacón-Barrantes, S., 2018. The 2017 México tsunami record, numerical modeling and threat assessment in Costa Rica. Pure and Applied Geophysics, 175, 1939-2950.

Dziewonski, A.M., and Anderson, D.L., 1981. Preliminary Reference Earth Model (PREM). Physics of the Earth and Planetary Interiors, 25, 297-356.

Fielding, E.J., Lundgren, P.R., Taymaz, T., Yolsal-Çevikbilen, S. and Owen, S.E., 2013. Fault-Slip source models for the 2011 M7.1 Van earthquake in Turkey from SAR interferometry, pixel offset tracking, GPS and seismic waveform analysis. Seismological Research Letters, 84 (4), 579-593.

Franco, S.I., Kostoglodov, V., Larson, K.M., Manea, V.C., Manea, M. and Santiago, J.A., 2005. Propagation of the $2001-2002$ silent earthquake and interplate coupling in the Oaxaca subduction zone, Mexico. Earth Planets Space, 57, 973 - 985.

Franke, D., Schnabel, M., Ladage, S., Tappin, D.R., Neben, S., Djajadihardja, Y. S., Müller, C., Kopp, H. and Gaedicke, C., 2008. The great Sumatra-Andaman earthquakes - Imaging the boundary between the ruptures of the great 2004 and 2005 earthquakes. Earth and Planetary Science Letters, 269 (1-2), 118-130.

Futterman, W., 1962. Dispersive body waves. Journal of Geophysical Research, 67, 5279 $-5291$.

GEBCO-BODC, "General Bathymetric Chart of the Oceans-British Oceanographic Data Centre". https://www.gebco.net”, Son erişim tarihi: Ekim 2018.

Geist, E.L., 1999. Local tsunamis and earthquake source parameters. Adv. Geophys., 39, 117- 209.

Geist, E.L. and Dmowska, R., 1999. Local tsunamis and distributed slip at the source. Pure and Applied Geophysics, 154, 485-512.

Geist, E.L. and Oglesby, D.D., 2014. Earthquake Mechanism and Seafloor Deformation for Tsunami Generation. Encyclopedia of Earthquake Engineering, doi: 10.1007/978-3642-36197-5_296-1.

Gica, E., Teng, M., Liu, P.L. -F, Titov, V.V. and Zhou, H., 2007. Sensitivity analysis of source parameters for earthquake generated distant tsunamis. Journal of Waterway, Port, Coastal and Ocean Engineering, 133 (6), 429-441.

Goldstein, P., Dodge, D., Firpo, M. and Minner, L., 2003. SAC2000: Signal processing and analysis tools for seismologists and engineers. In Lee W.H.K., Kanamori H., Jennings P.C. and Kisslinger C., Eds. Contribution to "The IASPEI International Handbook of Earthquake and Engineering Seismology", Academic Press, London. 
Goldstein, P. and Snoke, A., 2005. SAC availability for the IRIS community: Incorporated Research Institutions for Seismology Newsletter, v. 7, no. 1.

Guidoboni, E. and Comastri, A. 2005a. Catalogue of Earthquakes and Tsunamis in the Mediterranean area From the 11th to the 15th Century. INGV-SGA, Bologna.

Guidoboni, E. and Comastri, A. 2005b. Two thousand years of earthquakes and tsunamis in the Aegean are (from 5th BC to 15th century). International Symposium on the Geodynamics of Eastern Mediterranean: Active Tectonics of the Aegean Region. Abstract Book: Kadir Has University, 15-18 June, 2005, İstanbul, Turkey, p. 242.

Guo, R., Zheng, Y., Xu, J., Zhongshan, J., 2019. Seismic and aseismic fault slip associated with the $2017 \mathrm{M}_{\mathrm{w}} 8.2$ Chiapas, Mexico earthquake sequence. Seismological Research Letters, 90 (3), 1111-1120.

Gusman, A.R., Tanioka,Y., Maclnnes, B.T. and Tsushima, H., 2014. A methodology for near-field tsunami inundation forecasting: Application to the 2011 Tohoku tsunami. Journal of Geophysical Research: Solid Earth, 119, 8186-8206, doi:10.1002/ 2014JB010958.

Gusman, A.R., Mulia, I.E. and Satake, K., 2018. Optimum sea surface displacement and fault slip distribution of the 2017 Tehuantepec earthquake $\left(M_{w}\right.$ 8.2) in Mexico estimated from tsunami waveforms. Geophysical Research Letters, 45, 646-653.

Heidarzadeh, M., Ishibe, T. and Harada, T., 2018. Constraining the source of the $M_{w} 8.1$ Chiapas, Mexico earthquake of 8 September 2017 using teleseismic and tsunami observations. Pure and Applied Geophysics, 175, doi:10.1007/s00024-018-1837-6.

Howell, A., Jackson, J., Copley, A., McKenzie, D. and Nissen, E., 2017. Subduction and vertical coastal motions in the eastern Mediterranean. Geophysical Journal International, 211, 593-620.

IOC, 2017. Intergovernmental Oceanographic Commission, http://www.iocsealevelmonitoring.org, Son Erişim Tarihi: Ekim 2017.

Jamelot, A., Gailler, A., Heinrich, Ph., Vallage, A., Champenois, J., 2019. Tsunami Simulations of the Sulawesi $M_{w} 7.5$ Event: Comparison of Seismic Sources Issued from a Tsunami Warning Context Versus Post-Event Finite Source. Pure and Applied Geophysics, 176, 3351-3376.

Jiménez, C., 2018. Seismic source characteristics of the intraslab 2017 Chiapas-Mexico earthquake $\left(\mathrm{M}_{\mathrm{w}}\right.$ 8.2). Physics of the Earth and Planetary Interiors, 280, 69-75.

Kelleher, J., Sykes L. and Oliver J., 1973. Possible criteria for predicting earthquake locations and their application to major plate boundaries of the Pacific and the Caribbean. Journal of Geophysical Research, 78 (14), 2547-2585.

Kelleher, J. and McCann., W., 1976. Buoyant zones, great earthquakes, and unstable boundaries of subduction. Journal of Geophysical Research, 81, 4885-4896.

Kikuchi, M. and Kanamori, H., 1991. Inversion of complex body waves-III. Bulletin of the Seismological Society of America, 81 (6), 2335-2350. 
Lay, T., Kanamori, H., Ammon, C.J., Nettles, M., Ward, S. N., Aster, R.C., Beck, S.L., Bilek, S.L., Brudzinski, M.R., Butler, R., De Shon, H.R., Ekstrom, G., Satake, K. and Sipkin, S., 2005. The great Sumatra- Andaman earthquake of 26 December 2004. Science, 308, 1127-1133.

Lay, T., Ye, L., Kanamori, H., Yamazaki, Y., Cheung, K.F., Kwong, K. and Koper, K.D., 2013. The October 28, $2012 \mathrm{M}_{\mathrm{w}} 7.8$ Haida Gwaii underthrusting earthquake and tsunami: slip partitioning along the Queen Charlotte Fault transpressional plate boundary. Earth and Planetary Science Letters, 375, 57-70.

Liu, P.L.F., Woo, S.B. and Cho, Y.S., 1998. Computer programs for tsunami propagation and inundation. Cornell University, Ithaca.

Mansinha, L. and Smylie, D.E., 1971. The displacement fields of inclined faults. Bull. Seism. Soc. Am., 61, 1433-1440.

McCaffrey, R., Zwick, P. and Abers, G., 1991. SYN4 Program. IASPEI Software Library, 3, 81-166.

McNally, K.C. and Minster, J.B., 1981. Nonuniform seismic slip rates along the Middle America Trench. Journal of Geophysical Research, 86 (B6) , 4949-4959.

Mendoza, C., 1993. Coseismic slip of two large Mexican earthquakes from teleseismic body waveforms: Implications for asperity interaction in the Mihoacan plate boundary segment. Journal of Geophysical Research, 98, 8197-8210

Meriç, H.T., 2019. Source models of September 25, 2013 Acari-Peru $\left(M_{w} 7.1\right)$ and September 08, 2017 Chiapas-Mexico ( $M_{w}$ 8.2) earthquakes and Tsunami Simulations. Istanbul Technical University, Graduate School of Science and Engineering and Technology, MSc. Thesis, 82 sayfa, İstanbul, Turkey.

Mofjeld, H. O., Titov, V. V., González, F. I. and Newman, J. C., 2001. Tsunami scattering provinces in the Pacific Ocean. Geophysical Research Letters, 28 (2), 335-337.

Molnar, P. and Lyon-Caen, H., 1989. Fault plane solutions of earthquakes and active tectonics of the Tibetan Plateau and its margins. Geophysical Journal International, 99, 123-154.

Nishenko, S.P., 1991. Circum-Pacific seismic potential: 1989-1999. Pure and Applied Geophysics, 135 (2), 169-259.

NDBC, 2017. National Data Buoy Center. https://www.ndbc.noaa.gov, Son Erişim Tarihi: Ekim 2017.

Okada, Y., 1985. Surface deformation due to shear and tensile faults in a half-space. Bulletin of the Seismological Society of America, 75, 1135-1154.

Okal, E.A. 1988. Seismic parameters controlling far-field tsunami amplitudes: A review. Natural Hazards, 1, 67-96.

Okal, E.A., Fritz, H. M. and Sladen, A., 2009. 2004 Sumatra- Andaman tsunami surveys in the Comoro Islands and Tanzania and regional tsunami hazard from future Sumatra events. South African Journal of Geology, 112, 343-358. 
Okuwaki, R. and Yagi, Y., 2017. Rupture Process during the $M_{w} 8.12017$ Chiapas Mexico Earthquake: Shallow Intraplate Normal Faulting by Slab Bending. Geophysical Research Letters, 44, 11816-11823.

Pakoksung, K., Suppasri, A., Imamura, F., Athanasius, C., Omang, A. and Muhari, A., 2019. Simulation of the Submarine Landslide Tsunami on 28 September 2018 in Palu Bay, Sulawesi Island, Indonesia, Using a Two-Layer Model. Pure and Applied Geophysics, 176, 3323-3350.

Papadopoulos, G.A., Daskalaki, E., Fokaefs, A.i and Giraleas, N. 2007. Tsunami hazard in the Eastern Mediterranean: strong earthquakes and tsunamis in the east Hellenic Arc and Trench system. Natural Hazards and Earth System Sciences, 7, 57-64.

Ponce, L., Suarez, G. and Lomas, E., 1992. Geometry and state of stress of the downgoing Cocos plate in the Isthmus of Tehuantepec, Mexico. Geophysical Research Letters, 19, 773-776.

Ramírez-Herrera, M.T., Néstor C., Ruiz-Angulo, A., Melgar, D. and Zavala-Hidalgo, J., 2018. The 8 September 2017 Tsunami triggered by the $M_{w} 8.2$ Intraplate Earthquake, Chiapas, Mexico. Pure and Applied Geophysics, 175 (1), 25-34.

Ruiz-Constán, A., Galindo-Zaldìvar, J., Pedrera, A., Célérier, B., Marìn-Lechado, C., 2011. Stress distribution at the transition from subduction to continental collision (northwestern and central Betic Cordillera). Geochemistry Geophysics Geosystems, 12 (12), Q12002, doi:10.1029/2011GC003824.

Saltogianni, V., Gianniou, M., Taymaz, T., Yolsal-Çevikbilen, S. and Stiros, S., 2015. FaultSlip Source Models for the $2014 \mathrm{M}_{\mathrm{w}} 6.9$ Samothraki-Gökçeada Earthquake (North Aegean Trough): combining geodetic and seismological observations. Journal of Geophysical Research - Solid Earth, 120, doi:10.1002/2015JB012052.

Satake, K., 1988. Effects of bathymetry on tsunami propagation: application of ray tracing to tsunamis. Pure and Applied Geophysics, 126, 27-36.

Shaw, B. and Jackson, J., 2010. Earthquake mechanisms and active tectonics of the Hellenic subduction zone. Geophysical Journal International, 181 (2), 966-984.

Sibuet, J.C., Rangin, C., LePichon, X., Singh, S., Cattaneo, A., Graindorge, D., Klingelhoefer, F., Lin, J.Y., Malod, J., Maury, T., Schneider, J. L., Sultan, N., Umber, M. and Yamaguchi, H., 2007. The "Sumatra aftershocks" team, 26th December 2004 great Sumatra-Andaman earthquake: Co-seismic and post-seismic motions in northern Sumatra. Earth and Planetary Science Letters, 263 (1-2), 88-103.

Singh, S. K., Astiz, L. and Havskov, J., 1981. Seismic gaps and recurrence periods of large earthquakes along the Mexican Subduction Zone: A Re-examination. Bulletin of the Seismological Society of America, 71 (3), 827-843.

Singh, S. K., Shapiro M.N., Iglesias-Mendoza A., Cruz-Atienza V. and Pacheco J., 2000. Popocatepetl, an active volcano, reduce seismic hazard to Mexico City. Geophysical Research Letters, 27, 2753-2756. 
Song, C. and Ge, Z., 2019. 3D model backprojection of the $2017 \mathrm{Mw} 8.2$ Chiapas earthquake: a two-stage rupture with a barrier-induced velocity increase. Seismological Research Letters, 90 (3), 1121-1130.

Spagnotto, S., Alvarez, O. and Folguera, A., 2018. Static stress increase in the outer forearc produced by $M_{w} 8.2$ September 8, 2017 Mexico earthquake and its relation to the gravity signal. Pure and Applied Geophysics, 175, 2575-2593.

Tan, O. and Taymaz, T., 2006. Active tectonics of the Caucasus: Earthquake source mechanisms and rupture histories obtained from inversion of teleseismic body waveforms. In: Post-collisional Tectonics and Magmatism in the Mediterranean Region and Asia, Geological Society of America, Special Paper, 409, 531-578.

Tang, L., Titov, V. V., Wei, Y., Mofjeld, H.O., Spillane, M., Arcas, D., Bernard, E. N., Chamberlin, C., Gica, E. and Newman, J., 2008. Tsunami forecast analysis for the May 2006 Tonga tsunami. Journa of Geophysical Research, 113, C12015, doi:10.1029/2008JC004922.

Taymaz, T., Jackson, J. and Westaway, R., 1990. Earthquake mechanisms in the Hellenic Trench near Crete. Geophysical Journal International, 102, 695-731.

Taymaz, T., Jackson, J. and McKenzie, D., 1991. Active tectonics of the north and central Aegean Sea. Geophysical Journal International, 106, 433-490.

Taymaz, T., Wright, T.J., Yolsal, S., Tan, O., Fielding, E. and Seyitoğlu, G., 2007. Source characteristics of the 6 June 2000 Orta - Çankırı (central Turkey) earthquake: a synthesis of seismological, geological and geodetic (InSAR) observations and internal deformation of the Anatolian plate. in: The Geodynamics of the Aegean and Anatolia, Geological Society, London, Special Publication, 291, 259-290.

Titov, V. V., Rabinovich, A. B., Mofjeld, H. O., Thomson, R. E., González, F. I., 2005. The global reach of the 26 December 2004 Sumatra Tsunami. Science, doi: 10.1126/science. 1114576.

Ulrich, T., Vater, S., Madden, E.H., Behrens, J., van Dinther, Y., van Zelst, I., Fielding, E. J., Liang, C. and Gabriel, A.-A., 2019. Coupled, Physics-Based modeling reveals earthquake displacements are critical to the 2018 Palu, Sulawesi Tsunami. Pure and Applied Geophysics, 176, 4069-4109.

Ulutaş, E., 2013. Comparison of the seafloor displacement from uniform and non-uniform slip models on tsunami simulation of the 2011 Tohoku-Oki earthquake. Journal of Asian Earth Sciences, 62, 568-585.

Wang, X., 2009. User Manual for COMCOT version 1.7 (first draft), Cornell University.

Wells, D.L. and Coppersmith, K.J., 1994. New empirical relationships among magnitude, rupture length, rupture width, rupture area, and surface displacement. Bulletin of the Seismological Society of America, 84, 974-1002.

Wessel, P. and Smith, W.H.F., 1998. New, improved version of generic mapping tools released. Eos Trans. AGU, 79 (47), 579. 
Yagi, Y. and Kikuchi, M., 2000. Source rupture process of the Kocaeli, Turkey, earthquake of August 17, 1999, obtained by joint inversion of near-field data and teleseismic data. Geophysical Research Letters, 27, 1969-1972.

Yagi, Y., Nishimura, N. and Kasahara, A., 2012. Source process of the 12 May 2008 Wenchuan, China, earthquake determined by waveform inversion of teleseismic body waves with a data covariance matrix. Earth Planets Space, 64, E13-E16.

Ye, L., Lay, T., Bai, Y., Cheung, K.F., Kanamori, H., 2017. The $2017 \mathrm{M}_{\mathrm{w}} 8.2$ Chiapas, Mexico Earthquake: Energetic Slab Detachment. Geophysical Research Letters, 44, 11824-11832.

Yolsal, S., 2008. Girit-Kıbrıs Yayları ve Ölü Deniz Fay Zonu Çevresinde Oluşan Depremlerin Kaynak Mekanizması Parametreleri, Kayma dağılımları ve Tarihsel Tsunami simülasyonları. Doktora Tezi, 523 sayfa, ITÜ Fen Bilimleri Enstitüsü, İstanbul.

Yolsal, S. and Taymaz, T. 2010. Sensitivity analysis on relations between earthquake rupture parameters and far-field tsunami waves: Case studies in the Eastern Mediterranean region. Turkish Journal of Earth Sciences, 19, 313-349.

Yolsal-Çevikbilen, S. and Taymaz, T., 2012. Earthquake source parameters along the Hellenic subduction zone and numerical simulations of historical tsunamis in the Eastern Mediterranean. Tectonophysics, 536-537, 61-100.

Yolsal-Çevikbilen, S. and Taymaz, T., 2019. Source characteristics of the 28 September $2018 \mathrm{M}_{\mathrm{w}}$ 7.5 Palu-Sulawesi, Indonesia (SE Asia) earthquake based on inversion of teleseismic bodywaves. Pure and Applied Geophysics, 176, 4111-4126.

Yolsal, S., Taymaz, T. and Yalçıner, A.C., 2007. Understanding tsunamis, potential source regions and tsunami prone mechanisms in the Eastern Mediterranean. in The Geodynamics of the Aegean and Anatolia, Eds. Taymaz, T., Yılmaz, Y. and Dilek, Y., Special Publication, Geological Society, London, Special Publications, 291, 201-230.

Yolsal-Çevikbilen, S., Taymaz, T., Ulutaş, E., 2017. Aktif dalma batma zonlarında meydana gelen depremlerin kaynak mekanizması parametreleri, kayma/yırtılma dağılımları ve matematiksel tsunami simülasyonları. TÜBITTAK-ÇAYDAG 1001 Araştırma Projesi, Proje No: 114Y066, Final Proje Raporu, 354 sayfa.

Yolsal-Çevikbilen, S., Ulutaş, E. and Taymaz, T., 2019. Source models of the 2012 Haida Gwaii (Canada) and 2015 Illapel (Chile) earthquakes and numerical simulations of related tsunamis. Pure and Applied Geophysics, 176 (7), 2995-3033.

Zwick, P., McCaffrey, R. and Abers, G., 1994. MT5 Program. IASPEI Software Library, 4. 